Illinois State University

ISU ReD: Research and eData

Theses and Dissertations

3-10-2015

\title{
Measuring Predictors of Groupthink: Instrument Development and Validation
}

Richard Walter Baptist

Illinois State University, richardbaptist11@yahoo.com

Follow this and additional works at: https://ir.library.illinoisstate.edu/etd

Part of the Communication Commons, and the Organizational Behavior and Theory Commons

\section{Recommended Citation}

Baptist, Richard Walter, "Measuring Predictors of Groupthink: Instrument Development and Validation" (2015). Theses and Dissertations. 339.

https://ir.library.illinoisstate.edu/etd/339

This Thesis is brought to you for free and open access by ISU ReD: Research and eData. It has been accepted for inclusion in Theses and Dissertations by an authorized administrator of ISU ReD: Research and eData. For more information, please contact ISUReD@ilstu.edu. 


\title{
MEASURING PREDICTORS OF GROUPTHINK: INSTRUMENT DEVELOPMENT
}

\section{AND VALIDATION}

\author{
Richard W. Baptist
}

122 Pages

May 2015

Individuals in any organization will often find themselves working in groups, either by force, necessity, or through volunteering. Group work is something everyone must do, and learning how to make the best of every situation and group opportunity can be the difference between a positive or negative experience. This study explores the communication within decision-making groups where a poor outcome or decision occurred. By examining the concept of groupthink, we can enhance our understanding of the factors influencing the group decision-making process and how communication can benefit organizations. This specific study expands the current body of knowledge on groupthink by developing an instrument to effectively measure a group's tendency toward groupthink; a type of faulty decision-making. It examines the relationship between the concept of groupthink and the variables of highly cohesive groups, promotional leadership, conformity, concurrence seeking, anxiety, collective efficacy, hidden profiles, and trust, in an attempt to develop a scale to access a group's propensity to commit groupthink. 
MEASURING PREDICTORS OF GROUPTHINK:

INSTRUMENT DEVELOPMENT

AND VALIDATION

RICHARD W. BAPTIST

A Thesis Submitted in Partial

Fulfillment of the Requirements

for the Degree of

MASTER OF SCIENCE

School of Communication

ILLINOIS STATE UNIVERSITY

2015 
Copyright 2015 Richard W. Baptist 


\section{MEASURING PREDICTORS OF GROUPTHINK:}

\section{INSTRUMENT DEVELOPMENT}

AND VALIDATION

RICHARD W. BAPTIST

COMMITTEE MEMBERS:

Kevin R. Meyer, Chair

Lance Lippert

Daniel A. Cochece Davis 


\section{ACKNOWLEDGMENTS}

I would first and foremost like to thank my chair, friend, and mentor, Dr. Kevin Meyer, for his support and guidance, and for working with me thoroughly throughout the duration of completing this thesis. Dr. Meyer is someone I have admired since I arrived at Illinois State University, and he has taught me much throughout my career here. Additionally, his guidance has helped me to grow as a scholar and a person, and I truly appreciate Dr. Meyer working with me by teaching me along the way, and by ensuring that I was confident in my understanding of the procedures every step of the way.

Similarly, I would like to thank my committee member, Dr. Lance Lippert, for offering me support throughout the thesis process and all of graduate school. Dr. Lippert has also served as a mentor for me during graduate school, and was always committed to my success both academically and personally. He has worked with me on projects related to my research interests and has found ways for me to be involved in areas of the discipline that benefit me. Lastly, he offered feedback and suggestions for my thesis that improved the overall quality of the work.

I would also like to thank my final committee member, Dr. Daniel Cochece Davis. He offered invaluable feedback on my thesis that allowed the study to be successful, and was excited about the topic and committed to finding ways to better help me reach my goals. Additionally, he has always had my interests in mind and has 
provided me with advice and encouragement in many areas of life, for which I am extremely grateful.

I would like to extend a special thanks to my family, whose love and support have guided me through all of my schooling. My parents, Tammy and Bill, have always encouraged me to follow my dreams and they have supported me every step of the way. Without their assistance and belief in my ability to succeed, I would not be where I am today.

I would also like to thank Patty Franz for all of her help and guidance throughout my graduate school career. I certainly could not have done this and would not be here without her. Lastly, I offer my overwhelming gratitude to the staff of the School of Communication, my cohort, and all of the wonderful friends I have made here. Without their guidance and support throughout graduate school, I would not have a thesis. I am privileged to be a part of such a wonderful program and am humbled to have worked with so many wonderful people.

R.W.B. 


\section{CONTENTS}

Page

ACKNOWLEDGMENTS $\quad$ i

CONTENTS

TABLES Vi

CHAPTER

I. REVIEW OF LITERATURE 1

Groupthink 3

Five-step Casual Model 5

Critique of casual model $\quad 8$

Solutions to Groupthink $\quad 8$

$\begin{array}{ll}\text { Empirical Study of Groupthink } & 10\end{array}$

$\begin{array}{lr}\text { Case Studies } & 12\end{array}$

Experimental Studies $\quad 13$

Well-tested Variables $\quad 14$

Mixed Results 14

Debate about Groupthink Model 17

$\begin{array}{ll}\text { Groupthink Variables } & 19\end{array}$

Highly Cohesive $\quad 19$

Promotional Leadership $\quad 24$

Conformity 26

Concurrence Seeking 28

Anxiety $\quad 30$

Collective Efficacy $\quad 35$

Hidden Profiles 38

$\begin{array}{ll}\text { Trust } & 40\end{array}$ 
II. METHOD

Participants

Descriptive Statistics

Research Design and Procedures

Measures

Data Analysis

Estimates of Reliability

Reverse Coding of Items

III. FACTOR ANALYSIS

Highly Cohesive

Promotional Leadership

Conformity

Concurrence Seeking

Anxiety

Collective Efficacy

Hidden Profiles

Trust

Summary

IV. RESULTS

Correlation

Independent Samples $t$-Test

66

Multiple Linear Regression

Groupthink Occurrence Model

Summary 
Regression Models $\quad 82$

Hypotheses $\quad 82$

$\begin{array}{ll}\text { Implications } & 87\end{array}$

$\begin{array}{ll}\text { Theoretical Implications } & 87\end{array}$

Practical Implications $\quad 88$

Limitations $\quad 94$

Suggestions for Future Research 99

Conclusion $\quad 99$

$\begin{array}{ll}\text { REFERENCES } & 101\end{array}$

$\begin{array}{ll}\text { APPENDIX: Survey Questions } & 118\end{array}$ 


\section{TABLES}

Table $\quad$ Page

1. Composite Variables Measured in the Survey Instrument 50

2. Factor Loadings for Highly Cohesive Scale 56

3. Factor Loadings for Promotional Leadership Scale 57

4. Factor Loadings for Conformity Scale 58

5. Factor Loadings for Concurrence Seeking Scale 60

6. Factor Loadings for Anxiety Scale $\quad 61$

7. Factor Loadings for Collective Efficacy Scale 62

8. Factor Loadings for Hidden Profiles Scale 63

9. Factor Loadings for Trust Scale $\quad 64$

10. Groupthink Occurrence Regression Model Table 72

11. Beta Weights for Final Groupthink Occurrence Model 73

12. Groupthink Disaster Regression Model Table 76

13. Beta Weights for Final Groupthink Disaster Model 77 


\section{CHAPTER I}

\section{REVIEW OF LITERATURE}

Group work is a domain in which almost every individual will have multiple experiences. Learning how to properly develop and enhance decision-making processes within groups can be the difference between a positive or negative experience and outcome. According to Gunnarsson (2010), groups, teams, or committees make many of the decisions made in organizations. The benefits of group decision-making include generating more information and knowledge, producing more diverse opinions, and enhancing acceptance of a decision (Robbins \& Judge, 2011); however, not all of these things work out beneficially during group decision-making processes. The difference between good and poor decision-making is an important issue within the study of group communication. Many social psychologists have argued, "humans would do better without groups" (Buys, 1978, p. 123). "To err is human" is a cliché used by those who dismiss fiascoes, miscalculations, and disastrous results of a collective misjudgment (Janis, 1972, p. 2). According to Janis, "platitudinous thoughts about human nature do not help us to understand how and why human miscalculations are made" (p. 2). Instead, Janis also said, "groups can bring out the worst as well as the best in human decisionmaking" (p. 3). Learning how to make the most of these group experiences is something of vital importance in an increasingly interconnected social world. 
One of the more influential concepts about group decision-making processes is groupthink, which specifies several antecedents that function together to lead to poor decision-making. These antecedents include high group cohesiveness, a stressful situation, and various structural or administrative factors such as the insulation of the group, promotional leadership, a lack of sound decision-making procedures, and a lack of diversity or variety in values and perspectives of group members. Since it is difficult to clearly define most of its variables, operationalizing groupthink is also tough. Additionally, because there is no consensus about how to measure the variables associated with groupthink, there is a lack of standardization between measures and approaches to studying groupthink by researchers, making it challenging to consistently and accurately measure groupthink, or to compare and contrast results of groupthink studies. This is why developing an appropriate measure for the variables associated with groupthink, to better understand what predicts groupthink and test a group's propensity toward it, is so important.

Due to its negative nature, groupthink has garnered a large amount of attention in scholarship on group communication, and as a function to understanding conflict resolution and expressing disagreements in the larger scheme of communication, it is practical to study in the field. Considering the potential reach to groups not only in academia, but also in government, politics, and other important areas of society, groupthink is certainly worthy of analysis. Thus, by examining groupthink, one can begin to understand the factors influencing the occurrence of the phenomenon and, then, how it could be avoided. 
Understanding the predictors of and possible solutions to groupthink may also increase several positive dimensions of group interactions such as performance and satisfaction together. The present study develops a self-report survey instrument to effectively measure the propensity a group has toward groupthink, while the predictors at play serve as a guide, warning a group when the telltale signs of groupthink begin to emerge. The ultimate goal is to find the relationship between eight independent variables, how they lead to the explanation and prediction of groupthink, and how they are evident in the way groups communicate.

The first chapter will begin by revisiting Janis' $(1972,1982)$ groupthink model, then incorporate the eight symptoms and six decision-making defects of groupthink Janis determined to be synonymous with this phenomenon. Next, an overview of the history of groupthink research will be presented, followed by a conceptualization of the principal variables that are hypothesized to be essential to the present study and the study of groupthink: highly cohesive, promotional leadership, conformity, concurrence seeking, anxiety, collective efficacy, hidden profiles, and trust.

\section{Groupthink}

Communication is fundamental to people as social beings, and working together on tasks as a group or team is a major aspect of social life. Groups use communication to increase mutual understanding, define goal-oriented behavior, and coordinate individual behavior within groups; therefore, theories from communication science can help understand important communication processes and group approaches to behavior coordination, and where they might go wrong, as in cases when groupthink occurs. 
Irving Janis, a faculty member in psychology at Yale University, coined the term "groupthink" to describe how certain conditions can lead a group to be highly satisfied with what turns out to be an ineffective decision. Groupthink is a mode of thinking in which members of a highly cohesive group strive for unanimity and consensus, overriding their motivation to realistically appraise alternative courses of action (Janis, 1972, 1982). Cohesiveness is the degree of mutual interest a group has. It is usually a good thing as it can bring the members of a group together, but it has its dangers. For example, the more cohesiveness a group has, the more pressure it puts onto members of that group to maintain the cohesiveness through its communication. In turn, the group invests more of its energy in keeping this cohesiveness intact than it does in making the right decision. Janis $(1972,1982)$ identified the attack on Pearl Harbor, the Bay of Pigs Invasion, the escalation of the War in Vietnam, and the Watergate cover-up as examples of case studies on groupthink. Although Janis' $(1972,1982)$ analyses of groupthink focused primarily on political and military decisions, the potential for groupthink to occur in any organization is equally plausible (Finkelstein, 2003; Miller, 1990; Tasa \& Whyte, 2005). This is why the groupthink phenomenon has important ramifications for the study of both group and organizational communication.

However, before fully exploring groupthink, it has to be clear what constitutes a group. According to Moreland (2010), what separates groups from dyads is that groups do not form or dissolve as quickly, the way people feel emotions and express them are different, and the different phenomena that occur in groups are more complex. Based upon these arguments, a group is different from a dyad and identified by having three or more members. For a group to form, relationships among three or more people are 
needed, and these include relationships between each pair of people, relationships between each person and the subgroup(s) to which they belong, and relationships between each individual and the group as a whole (Moreland, 2010). Within a dyad, damage to a single relationship is enough to make the dyad dissolve, but if there is damage to only one relationship in a group, the group can still survive. This complexity of group communication is part of what makes studying groups so multifaceted, intricate, and interesting to researchers. The challenge of studying groups is complicated even further when trying to distinguish or compare between groups and teams, and between face-to-face, virtual, or dispersed groups. Also of interest to this study is distinguishing face-to-face groups from virtual groups to test for potential differences between participant responses.

\section{Five-step Casual Model}

Groupthink is a five-step causal model represented by five stages. Janis and Mann (1977) first developed this model. The first stage is the antecedent stage, which includes the group having high levels of cohesiveness, structural defects, and being involved in a proactive situational context. Structural defects include insulation, a lack of leader impartiality, a lack of procedural norms, and member homogeneity. Provocative situational contexts include low group efficacy and high stress. The second stage of the groupthink model is concurrence seeking, which is the tendency of group members to agree openly even if they privately disagree. The third stage is when the group experiences any or all of the eight symptoms of groupthink, which are collective rationalizations, pressure to conform, the emergence of mindguards, biased perceptions of the out-group, self-censorship, an illusion of invulnerability, an illusion of morality, 
and an illusion of unanimity. The fourth stage of the groupthink model is when the group exhibits the six decision-making defects, which are the failure to examine alternative ideas, the failure to examine preferred alternatives, having a selected bias when processing information, having no contingency plans, rejecting opinions of experts, and failing to reexamine rejected alternatives. The final stage of the groupthink model is a poor decision outcome.

The first stage of the groupthink model, the antecedent stage, is deserving of closer explanation. Janis (1982) said that groupthink is most likely to occur when three antecedent conditions are present. Cohesiveness is the first and most important of these antecedent conditions, and is what Janis called the greatest single hazard that can cause groupthink to occur. The second antecedent is organizational structural faults, which include insulation of the group, a lack of impartial leadership, a lack of systematic or procedural group norms, homogeneity of group members, and narrow parameters on acceptable solutions set by the leader of the group. Janis argued that the more a leader communicates and promotes their own preferred decision, the more likely it is that the group will arrive at a consensus without fully examining other potential options. The third antecedent is situational factors, which include high stress from external factors and temporary low self-esteem induced by recent failures, excessive difficulties, or moral dilemmas. Despite his assertion about the importance of high levels of cohesiveness, Janis said that groupthink could not occur if any or all of the antecedents were not present; thusly, Janis portrayed all antecedents as equally important.

Groupthink refers to a premature striving by members of a group to reach a unanimous agreement on a decision or course of action. Groupthink is undesirable as it 
cuts off necessary and important considerations or communication of the benefits and consequences of the different decision options (Ahlfinger \& Esser, 2001). Groupthink is identifiable by eight symptoms; each representing different ways group members can try to avoid or reduce the anxiety associated with decision-making and protect their selfesteem (Janis, 1982). These symptoms are viewable in three types. Type I symptoms involve overestimating the group, meaning that group members share an illusion of their invulnerability and unquestioned belief that their cause is just. Type II symptoms involve close-mindedness, meaning that group members collectively rationalize and avoid information that is inconsistent with their preferred choice and stereotype enemies as stupid or weak. Lastly, Type III symptoms involve a pressure toward uniformity, meaning that members of the group often self-censor their own concerns about the group's choice, creating and adding to a shared illusion of the group being unanimous in its acceptance of a majority decision. In addition, the group can communicate direct pressure on those who express dissenting viewpoints, and members may additionally take on the role of mindguards to "protect the group" from outside information which could threaten or challenge the confidence of the group's decision (Ahlfinger \& Esser, 2001). Janis (1972) said that the frequency and pronouncement of the symptoms of groupthink are direct predictors of the quality level of a group's decision. "The more frequently a group displays the symptoms, the worse the quality of its decisions will be. Even when some symptoms are absent, the others may be so pronounced that we can predict all the unfortunate consequences of groupthink" (Janis, 1972, p. 198). The symptoms of groupthink as proposed by Janis will serve as the jumping off point for the present study, but only a few of them are actual variables used as predictors of groupthink in the current 
instrument. These decisions were based upon the frequency of attention and overall support each groupthink variable has garnered since Janis' $(1972,1982)$ original conception of the model, and takes into consideration new variables proposed in alternate groupthink models.

Critique of casual model. Part of the need for the current study and reason to research in this area is the problematic nature of Janis' $(1972,1982)$ casual model. Simply put, groupthink does not always occur given the same set of circumstances or with the same predictors in place. What leads to groupthink does not always cause it, making it difficult to establish causality in any line of groupthink research. Therefore, a predictive model, stated in a more tentative manner, with a focus on the group's communication process and the skills one can learn to enhance their group decision, as opposed to the result itself, is more appropriate.

\section{Solutions to Groupthink}

There are nine steps to solving the groupthink problem in decision-making groups. These steps were proposed by Janis $(1972,1982,1989)$. The first step is to encourage everyone in the group to be a critical evaluator and to express reservations during the decision-making process. Second, do not have the leader state a preference up front. Third, set up several independent and separate policy making groups. The fourth step is to divide the group into subgroups, and the fifth step is to discuss what is happening with others outside of the group. Inviting outsiders into the group to bring in fresh ideas is the sixth step, and assigning an individual at each meeting to be the devil's advocate is the seventh step. The eighth step is to spend considerable time surveying 
warning signals. The final step to solving the groupthink problem as proposed by Janis is to hold a second-chance meeting to reconsider decisions before finalizing them.

Some of Janis' $(1972,1982,1989)$ recommendations to prevent groupthink have been widely accepted, such as appointing a devil's advocate, introducing outside voices and allowing brainstorming to occur without judgment or criticism. However, throughout the years, his original concept has been criticized, especially the conditions he described as necessary for groupthink to occur, such as internal cohesion, crisis, pressure, group insulation and members with similar ideologies and backgrounds (Cohen \& DeBenedet, 2012). These critiques of the proposed model, and subsequent changes, such as Whyte's (1998) and Moorhead, Ference, and Neck's (1991) models , work as the theoretical basis for the argument of developing a groupthink measure.

In sum, groupthink is more likely to emerge when groups are overly cohesive and try to reach consensus prematurely. It arrives out of a culture of self-censorship and mindguards, which are individuals who communicate to try to shut down the ideas of others and promote a consensus. It involves a high amount of overconfidence, which is when the group thinks "we cannot possibly all be wrong," leading to a potentially disastrous decision or nagging problem. This topic is important to study from a communication perspective because an absence of effective communication and disagreements are what allow groupthink to take hold, and because the predictor variables in this study, conceptualized and operationalized from a communicative lens, offer a way to study the phenomenon from a forward thinking outlook. 


\section{Empirical Study of Groupthink}

Currently, work is still needed to test, be able to measure, and further understand groupthink. Many of the original components, such as the different antecedents, of the theory have been questioned, examined, and have had changes proposed to them. One of the most influential and often cited changes to the original groupthink model was Whyte's (1998) replacement of cohesiveness with self-efficacy in a new model. According to Tetlock, Peterson, McGuire, Chang, and Field (1992), there is strong evidence that Janis' $(1972,1982)$ depiction of the groupthink model and functioning of the decision making groups he described is both accurate and consistent with that of other historical observations. However, according to Whyte (1998), the evidence is far less convincing that the groupthink model provides the best explanation for events of decision making that have produced disastrous outcomes. Moorhead and Montanari (1986) said that empirical analysis has seldom completely supported Janis' original model and conclusions. Perhaps one reason for this is the failure of Janis to develop a concise theoretical framework in his original book. In his 1982 version of groupthink, Janis shows an illustrated model and discusses the theoretical framework, allowing for a more precise interpretation of the causal sequence he alluded to in his 1972 work (Moorhead \& Montanari, 1986). Additionally, groupthink has been studied within a laboratory paradigm (e.g., Cline, 1990; Courtright, 1978), which adds to the perspectives of how it can be tested.

Since groupthink mainly deals with fiascos, or disastrous decisions or outcomes, individuals involved with the decision generally look back on the decision-making process, and researchers who study these decisions are prone to look back on events after 
the fact. This is known as retrospective sensemaking (Henningsen, 2002), which means scholars attempt to retroactively understand or cognitively process their environment after something has occurred (Louis, 1990). Sensemaking approaches say that after individuals act, they use information from their surroundings and from their own experiences to rank and understand their performance. Guzzo, Wagner, Maguire, Herr, and Hawley (1986) found that when one provides participants with information about a negative group outcome, the participants also infer a negative decision-making process had occurred within the group. This is important to take into consideration to understand why people are prone to make certain evaluations about their past performances or group activities.

Groupthink can be studied in a laboratory, but the results of such studies have been inconsistent and include deviations from Janis' $(1972,1982)$ original model. According to Park (2000), groupthink has received little support in laboratory settings, despite its far-reaching and influential nature. Research on groupthink has tended to look at only limited components of the groupthink model (e.g., Bernthal \& Insko, 1993; Callaway \& Esser, 1984; Cline, 1990; Courtright, 1978; Flowers, 1977; Fodor \& Smith, 1982; Leana, 1985). Additionally, some studies only look at factors outside of the model (e.g., Kroon, Hart, \& Kreveld, 1991; Kroon, Kreveld, \& Rabbie, 1992). Despite all of this, Janis (1982) said that groupthink occurs in groups with few deletions or changes from his proposed model. Aside from its prominence in decision-making literature, experimental support for the groupthink model has been weak at best, even when it is fully tested. On the other side, case studies and content analyses have produced more 
support for groupthink (Park, 2000). Thus, there is need for a more consistent way to measure the phenomenon.

\section{Case Studies}

An increasing number of case studies have applied groupthink, most of which review political and military decisions similar to the cases Janis $(1972,1982)$ originally evaluated. However, the breadth of the application of groupthink case studies continues to expand, as case studies have been completed on organizational decisions, like the baseball umpire strike of 1999 (Koerber \& Neck, 2003), organizational strategies, and fraudulent behavior of organizations. Most case studies only use a subset of the groupthink model, usually the symptoms of groupthink (Rose, 2011). Additionally, case studies often involve a retrospective application to decision fiascos and groupthink (e.g., Hensley, \& Griffin, 1986; Moorhead et al., 1991; Neck, 1996; Neck, Godwin, \& Spencer, 1996; Neck \& Moorhead, 1992). Most case studies on groupthink focus on governmental, military, and business decision-making disasters.

Case study researchers usually look for the presence of the antecedent conditions and symptoms of groupthink in real-world scenarios where defective decision-making was apparent. For example, Kramer (1998) used new evidence to re-analyze the Bay of Pigs failure; Moorhead et al. (1991) examined the Challenger tragedy; and Eaton (2001) considered two cases from British corporate management. These researchers found some of the antecedent conditions of groupthink related to the presence of groupthink symptoms, but only in differing combinations. Although their results provide general support for the groupthink model, what this means is that while groupthink does indeed 
occur from time to time, the factors or predictors that trigger groupthink are unclear or at the minimum vary in their effect in different situations.

\section{Experimental Studies}

There are less than 25 studies identified as experiments addressing various groupthink elements. Most studies select participants with little to zero history and/or future, and little to no cohesion, put them into groups of three to six, and then have the participants complete a decision-making task of some type, usually with a time pressure of 20 to 40 minutes. Additionally, questionnaires are implemented usually before and after the decision-making task, and, lastly, video or audio tapes of the decision-making process are analyzed (Rose, 2011). Despite this number of empirical studies on groupthink, there is very little agreement among researchers on the validity of the model (Park, 2000).

Laboratory studies have generally tested the presence and strength of linear relationships between antecedent conditions and the symptoms of groupthink. Similar to the results of groupthink case studies, experimental studies on groupthink provide only partial support for the model. Neck and Moorhead (1995) said that most of the studies on groupthink focus on interactive effects of cohesiveness and structural faults. Neck and Moorhead, as well as Aldag and Fuller (1993) and McCauley (1989), showed that the best predictors of groupthink were a closed leadership style and a lack of precise procedures for decision-making. Longley and Pruitt (1980) found that the presence of structural faults increased the tendency for early development of a norm toward a certain decision in cohesive groups, which might explain the symptoms of bad or defective decision-making in groups. Lastly, closed or directive leaders who discourage diverse 
opinions and promote their own favored opinion induce fewer suggestions from their group (Flowers, 1977; Leana, 1985). This emphasis on closed, directive, or promotional leadership serves as the basis for one of the present study's hypothesized variables.

\section{Well-tested Variables}

The three variables of groupthink tested the most are group cohesion, group insulation, and impartial leadership. Tests of impartial leadership have produced consistent support of the groupthink model, as lower-power leaders (Fodor \& Smith, 1982), open-leaders (Flowers, 1977), and non-directive leaders (Leana, 1985), have all been shown to facilitate discussion and the generation of new ideas. Group insulation has been found to reduce decision quality (Moorhead \& Montanari, 1986). Lastly, tests on group cohesion have produced mixed results (Rose, 2011). Bouncing off this information, promotional leadership and highly cohesive groups are two of the variables hypothesized in the present study to be key predictors of groupthink.

\section{Mixed Results}

The vast majority of research on groupthink examines only disastrous or negative outcomes; however, a growing number of scholars (e.g., Flippen, 1999; Hirokawa, Gouran, \& Martz, 1988; Kramer \& Dougherty, 2013) have argued that groupthink does not always lead to a less than optimal result. Groupthink is usually only considered when the outcome of a group decision is disastrous, and this is due to the early tradition of work on groupthink set forth by Janis (1972). According to Turner and Pratkanis (1998), the defining characteristic of most groupthink research is that groupthink results in extremely defective decision-making by the group. Peterson, Owens, Tetlock, Fan, and Martorana (1998) even said, "groupthink is the primary cause of fiasco in the modern 
world” (p. 273). However, Flippen, in a study of the Bay of Pigs invasion, stated that groupthink does not necessarily result in bad decisions. This is the key part of the catch22 involved with studying groupthink and attempting to develop an instrument to measure it. If the same symptoms do not always lead to a bad decision, then it can be tough to report it as such or even look back at the experience as groupthink retrospectively.

Due to a focus on bad or disastrous decisions, instead of examining the communication process associated with decision-making, most of the research on groupthink locates examples of poor decision-making outcomes and works backwards through retrospective sensemaking to find evidence of groupthink (Fuller \& Aldag, 1998). Kramer and Dougherty (2013) concluded that groupthink always involves poor decision-making processes, but that groupthink can also lead to negative, ambiguous, or even positive or successful outcomes. This suggests that research on groupthink should focus more on the communication process of the group, rather than the decision outcome. That is what this study attempts to address.

One of the other challenges with studying groupthink is the use of retrospective sensemaking as opposed to implementing a measure to look at it from a forward perspective. According to Kramer and Dougherty (2013), the previous research on groupthink represents a bias because nearly all typical examples of groupthink begin with negative or disastrous outcomes, and then work to examine, retrospectively, the faulty decision-making processes. Although Kramer and Dougherty admitted that using groupthink decision-making processes increased the chances of poor decisions and negative outcomes, the increased probability of a negative outcomes does not 
automatically cause a negative outcome every time. According to Hirokawa et al. (1988), the same groupthink processes leading to the Challenger disaster occurred on the July 1985 space shuttle flight, on which the O-rings came dangerously close to failing because of cold temperatures; however, the difference in the outcomes was due to almost random, unpredictable factors, rather than differences in the decision-making processes.

There have been a few other studies regarding groupthink and the Challenger disaster. Esser and Lindoerfer (1989) studied the Challenger accident through the lens of groupthink and used the Presidential Commission's report on the shuttle's accident as their data. Of the 88 statements drawn from the record, Esser and Lindoerfer identified 39 as instances of groupthink. Although Esser and Lindoerfer did not find all of the symptoms of groupthink in their analysis, two symptoms that were rather apparent were putting direct pressure on dissenters and mindguarding. Esser and Lindoerfer pointed out that "groupthink does not require all observable antecedents and consequences to be present in order for it to occur" (p. 176). These types of comments about groupthink are just another example of Janis' $(1972,1982)$ original model not being fully accepted by empirical research.

Another analysis of the Challenger accident and groupthink found that time pressure and leadership style are two moderating variables that should be considered when it comes to groupthink cases. Moorhead et al. (1991) studied the Challenger accident, but looked at the Level 1 Flight Readiness Review meeting. They found that the report they looked at showed "enough evidence of the antecedent conditions, the symptoms, and the decision-making defects to support a conclusion that the decision to launch can be classified as a groupthink situation" (Moorhead et al., 1991, p. 549). 
Additionally, they proposed two additional variables that act as moderators to group characteristics: time pressure and leadership style. According to Moorhead et al., the most effective leadership style for avoiding groupthink is "a strong, demanding leader who forces critical appraisal of all alternatives" (p. 549). To illustrate the impact of these two additional variables, the authors constructed a revised groupthink model. This new model is just one of the many types of proposed changes that groupthink has been subject to over the years, but its contributions are of great importance to the study of groupthink. Therefore, leadership style is considered as a predictor variable in this study, while time pressure is accounted for jointly with the proposed independent variable of anxiety.

\section{Debate about Groupthink Model}

Several articles have been written addressing the status of Janis' $(1972,1982)$ groupthink model. As Paulus (1998) said, "the model represents a brilliant construction founded in part on the existing group dynamics literature" (p. 371). Raven (1998) said he "hoped the work by Janis and his followers would sensitize policy makers and other decision groups about what they might do to counter the effects of groupthink" (p. 360). However, groupthink also has its critics. Baron (2005) said, "after many years of investigation, evidence has largely failed to support the formulation's more ambitious and controversial predictions" (p. 219). As Henningsen, Henningsen, Eden, and Cruz (2006) stated, "questions can be raised as to the utility of using groupthink theory before research" (p. 62). Lastly, Fuller and Aldag (1998) said, "groupthink is a compelling myth. Like other myths, it tells of things that never were but always are. How did we come to so widely and gladly accept it in the absence of compelling evidence" (p. 177)? These 
reviews effectively highlight the controversy and disagreements surrounding groupthink and the current state of the model.

Over a period of several decades, the groupthink model has generated a considerable amount of research and writing. However, the results of these studies only provide partial support of the model (Aldag \& Fuller, 1993; McCauley, 1989; McCauley, 1998). Additionally, many of the variables originally associated with groupthink are flimsy in their conceptual definitions and connections to the phenomenon. Similarly, Rose (2011) suggested a problematic issue with operationalizing groupthink is that most of its variables are not well defined. Because of this, researchers have had to develop their own measures and unique approaches to studying groupthink. Therefore, no consensus exists as to how to operationalize the antecedents of groupthink or how to measure the other variables (Esser, 1998). The lack of standardization makes it very difficult to be able to compare, contrast, or combine results of studies. Another problem is the difficulty in creating the kind of cohesive group Janis' (1982) original model uses. Not only had Janis sought to clarify and improve his model, but so have numerous other researchers and studies. Although there have not been many recent studies looking to reexamine or improve the groupthink model, the work being done in this area is certainly not complete. Most studies use ad hoc groups, but these groups have limited cohesion among members of the group as they are put together for the sake of the study and are not allowed to work together long enough to fully develop the cohesiveness needed for true groupthink to occur. The previous information about the history of the study of groupthink and its lack of clear and consistent results due to a lack of standardization of the variables associated with groupthink, showcases the necessity of developing a new 
instrument to measure the variables associated with groupthink through a communication perspective. Thus, two research questions are posited to drive the focus for this study:

$\mathrm{RQ}_{1}$ : What is the factor structure of the groupthink instrument?

$\mathrm{RQ}_{2}$ : What is the reliability of the groupthink instrument, and any subscales that are derived?

Relatively speaking, groupthink has stood the test of time. As it stands, groupthink is considered by many to be one of the most important group communication problems. The implications groupthink has on organizations, organizational communication, and group work within organizations are well understood; yet it has not been conceptualized or studied in such a way that it can be measured consistently. The present study will seek to do just that by clearly defining the concepts hypothesized to be evident in groupthink groups. This study seeks to measure groupthink in a way that allows it to access a group's predisposition to an outcome or nagging problem characterized by groupthink.

\section{Groupthink Variables}

\section{Highly Cohesive}

One of the more prominently associated and most often studied variables associated with groupthink is group cohesiveness. Janis (1972) originally identified high group cohesiveness as the "chief culprit" behind groupthink and bad decisions. He said, "the more ambiguity and esprit de corps among members of a group, the greater is the danger that independent, critical thinking will be replaced by groupthink" (p. 13). Moorhead and Montanari (1986) showed the importance of utilizing groups that had already been together for a significant amount of time, interacting and making highly 
significant decisions together, to study groupthink; whereas, other research efforts try to quickly induce cohesion by bringing together ad hoc groups. Since cohesiveness is the primary antecedent condition of groupthink, it must develop over time and be present in some degree before the decision situation in which groupthink might occur for it to be truly "antecedent" (Moorhead \& Montanari, 1986). This is the problem researchers encounter when trying to conduct experimental studies on groupthink; however, an instrument allowing participants to reflect on their group experiences that likely involved high levels of cohesion has the potential to be more successful at getting at the concept of groupthink.

When it comes to communication, it is important for groups to remain critical and ask questions during deliberations. According to Glaser (1993), groupthink seems to develop as a group becomes more cohesive and less critical of its own decisions. For example, a group may decide on a plan of action that only a few of the members propose and support, but without debate or critical thinking, the rest of the group goes along with the plan due to a greater concern for unanimity and solidarity, outweighing the desire to discuss other, and maybe more valid, alternatives. The result of a group believing in the correctness of a position and ignoring conflicting viewpoints is that the decision might be of such poor quality that it fails to live up to its intended purpose and may even create a more serious problem (Glaser, 1993). Cohesion is essentially a controlling force within groups, and that compliance toward the group or the accepted authority tends to be very high in cohesive groups (Hackman, 1992). According to Janis (1982), at the extreme end of the cohesion continuum, cohesiveness becomes an ingredient in groupthink where the group focuses more on the preservation of the group and their status within the group 
instead of efficient and effective engagement in the task. Turner, Pratkanis, Probasco, and Leve (1992) said that this process is rooted in identity preservation. Hackman concluded that highly cohesive groups will be less likely to generate truly innovative ideas or approaches to a task among themselves since individual effort and attention is consumed with staying within the boundaries set by group norms and experiences within the group. No one in the group wants to be the person who, simply put, "rocks the boat." This leads to the present study's first hypothesis:

$\mathrm{H}_{1}$ : As group cohesion increases, the chances of committing groupthink also increases.

Due to the confusion over groupthink and many of its variables, some researchers have argued against the inclusion of group cohesiveness in the groupthink model. Hogg and Hains (1998) proposed that previous research on groupthink had failed to clarify the causal role of group cohesiveness in groupthink due to a failure of being able to distinguish cohesiveness from friendship. To fix this, Hogg (1992) used social identity theory to create a conceptual distinction between positive regard (personal attraction, friendship) and solidarity (depersonalized social attraction, true group cohesiveness). They predicted that group identification and social attraction would be associated with the symptoms of groupthink because they are associated with depersonalization, which reinforces symptoms of groupthink such as a general striving for conformity, concurrence seeking, and agreement. They also said that personal attraction would not be associated with groupthink because it is associated with individuality and interpersonal differentiation, none of which are symptoms of groupthink. Hogg and Hains said that it is important to note that the topic of discussion in their study was difficult, as many 
different arguments could be raised, there was no obvious best solution, there were moral implications involved, and the decision had to be produced under time pressure. Hogg and Hains' study found friendship to be weakly and negatively associated with the symptoms of groupthink, while group identification and social attraction were strongly; however, with some exceptions, positively associated with the symptoms of groupthink. This study is important because it works as an early step in trying to clarify the role of cohesiveness in groupthink.

Adding to the understanding of what it takes for groups to achieve cohesiveness is the notion of entitativity. Entitativity is the degree to which members of a group recognize or legitimize being a part of said group (Mullen \& Copper, 1994). In other words, entitativity is the level of perceived "group-ness" that a member feels toward the group. The significance of this is that the more perceived entitativity members have toward the group, the stronger the group's cohesion will be. Mullen and Copper suggested that cohesion is stronger among groups who have entitativity and a "higher degree of group-ness" (p. 213). The more group members legitimize the group, the stronger the bond will be between members because they recognize the group to be real. If someone does not perceive the group to be legitimate, they will not cooperate as much with fellow group members because they do not value the group. Those who do not cooperate may be likely to play the role of the devil's advocate; which is in opposition to those who choose to cooperate and go along with the group, potentially contributing to groupthink.

When looking to increase group cohesion, it is important to note that there are a number of ways to improve it. Cohesiveness is higher in smaller-sized groups 
(Widmeyer, Brawley, \& Carron, 1990), enhanced by self-sacrifice (Prapavessis \& Carron, 1997), increased by participation in team goal setting (Brawley, Carron, \& Widmeyer, 1993), and is improved by democratic leader behavior (e.g., Kozub, 1993; Westre \& Weiss, 1991). Additionally, according to Williams and Hacker (1982), the relationship between cohesion and satisfaction is also reciprocal. Other reasons to promote cohesion are that greater cohesion has been related to collective efficacy (e.g., Paskevich, Brawley, Dorsch, \& Widmeyer, 1999), tolerance of the negative impact of disruptive events (e.g., Brawley, Carron, \& Widmeyer, 1988), assuming responsibility for negative outcomes (e.g., Brawley, Carron, \& Widmeyer, 1987), conformity to group norms (e.g., Shields, Bredemeier, Gardner, \& Boston, 1995), and adherence behavior (Prapavessis \& Carron, 1977). However, despite all of these so-called positive aspects of cohesiveness, too much of these aspects and too much cohesiveness may not always help to lead to a better group performance.

Cohesiveness also has its drawbacks, and it is important to recognize that the negative consequences associated with group cohesiveness are very real and too prominent to ignore. Paskevich, Estabrooks, Brawley, and Carron's (2001) study related cohesion to a pressure to conform, groupthink, and deindividualization. In addition, according to Paskevich et al., one reason why the negative consequences of cohesion have not been studied or even acknowledged very often is that researchers have accepted, incorrectly, that cohesion is always beneficial and, therefore, encouraged it. Additionally, cohesiveness is often linked to the skills and immediacy behaviors produced by the group leader. However, when the group leader improperly manages group communication processes or puts the focus on herself/himself, groupthink becomes a very real risk. 


\section{Promotional Leadership}

Of all of the antecedents of groupthink, the one that has received the most empirical study is the leader's promotional stance. Flowers (1977), in one of the first laboratory studies on groupthink, trained confederates to lead groups either by promoting their own preferred choice or by encouraging group members to express any and all possible viewpoints. As predicted, Flowers found that groups with leaders who communicate in a way that promotes their own preferences and viewpoints discussed fewer facts and brought up fewer solutions than groups with a leader who encouraged the expression of different viewpoints. Similarly, Fodor and Smith (1982) assigned group leaders based on their need for power. What they found was that in groups where the leader had a high need for power and, therefore, was likely to communicate in a way that promoted their own viewpoint, discussed fewer facts, proposed fewer alternative solutions, and expressed fewer moral concerns than groups with leaders who had lower needs for power. Lastly, Moorhead and Montanari (1986) used a path analysis to find that groups with more promotional leaders were more likely to discourage dissenters and adopt an illusion of morality than groups with less promotional leadership. Moreover, Esser (1998) said that there is support for the hypothesis of groupthink that promotional leadership indeed relates to the presence of groupthink symptoms, symptoms of poor decision processes, and poor decision quality.

The leadership-groupthink relationship is one area that has particularly seen an expansion of research. In an attempt to extend understanding of the leadership-groupthink relationship, Ahlfinger and Esser (2001) examined the effect of leadership promotion and a predisposition toward conformity in members on the characterization of the group 
process. The study's first hypothesis, which said that groups whose leaders promoted their own preferred solutions would be more likely to experience groupthink than groups with non-promotional leaders, only received partial support. However, groups with promotional leaders did produce more symptoms of groupthink, discussed fewer facts, and reached a decision more quickly than group with non-promotional leaders. Overall, their study provides support for the groupthink hypothesis regarding the effects of promotional leadership, but does not support the hypothesis that groups of people who are predisposed to conform would be more susceptible to groupthink than groups of less conforming members. However, this is still important because it suggests further development of better ways to measure groupthink indicators (i.e., groupthink symptoms and symptoms of poor decision-making). This idea ultimately leads to the development of the present study's second hypothesis:

$\mathrm{H}_{2}$ : Groups whose leader communicates in a way that promotes their preferred choice are more likely to commit groupthink.

Another difference in leadership is the effects of a participative group leader compared to a more directive leader. Cruz, Henningsen, and Smith (1999) found that directive leaders could sway hidden profile groups to show strong support for a poor decision more often. Additionally, Larson, Foster-Fishman, and Franz (1998) discovered that groups with participative leaders had better information sharing than those with directive leaders. This is consistent with assertions about the effect of directive leaders on information sharing and decision quality in groupthink. As by-products of promotional leadership, conformity, self-censorship, and sometimes a false consensus can become a side effect of improper group communication processes. 


\section{Conformity}

When members of a group perceive that they have a unanimous decision, they become more susceptible to conclude early. If their perception of unanimity is illusionary, then defects in their decision-making process, like failing to appraise alternative decisions thoroughly, can happen. According to Courtright (1978), "groupthink groups attempt to maintain harmony at the expense of critical decisionmaking” (p. 243). A major way in which this concept manifests itself through communication during the group decision-making process is self-censorship.

Related to conformity is the circumstance when groups begin to put pressure on and influence dissenters. Janis (1982) considered groupthink to be the result of a nondeliberate conformity where group members come to believe that their own reservations about the preferred group decision are not correct. His inclusion of direct pressure on dissenters as a symptom of groupthink suggests that the groupthink process of influence can also involve public compliance without private acceptance of the group's answer. Because of this, McCauley (1989) defined groupthink as "premature consensus seeking that may involve internalization, compliance, or both" (p. 251). When group members begin to doubt themselves or even question their own beliefs, serious problems begin to emerge that can cause enormous damage to the group and its decision.

Related to group pressure on dissenters is when the decision-making process includes communicative elements of conflict and hostility. According to Courtright (1978), the presence or absence of disagreement, meaning conflict or hostility, among group members may be the best discriminator between groupthink and non-groupthink groups. Members of groups often impose pressures on each other, which can lead to a 
false consensus, rather than the truth. A study by Anderson and Martin (1999) found that group members who tend to argue only the issues or problems, instead of communicating to put down others in the group, also perceive the other group members as experiencing satisfaction with the group's communication and reaching consensus. When discussing issues, it is easier for group members to either know or perceive that they have reached a consensus. Thus, argumentative members contribute to a positive communication climate due to their willingness and ability to take positive and constructive stands on group tasks. Janis (1982) said that groups whose members can argue issues freely would also be able to minimize their chances for groupthink. However, Anderson and Martin stressed the difference between argumentativeness, which is positive, and verbal aggressiveness, which is not, because it can lead to attacking other groups members directly and personally. They said that behaving in socially desirable ways in groups could inhibit constructive arguing. However, group members may perceive that they are not getting along if too much arguing occurs, and that group members may respond even more negatively toward an aggressive person in their group who just seems to want to disagree all of the time.

It is reasonable to think that certain types of individuals would be more or less susceptible to conformity influences. Callaway, Marriott, and Esser (1985) showed that groups composed of highly dominant members would be able to resist the conformity pressures which characterize groupthink. On the other side, groups made up of members who depend upon the approval of others to validate their own actions and therefore are predisposed to conformity, would be particularly likely to fall victim to groupthink (Callaway et al., 1985). One way to measure an individual's predisposition to conformity 
is to use the Concern for Appropriateness scale developed by Lennox and Wolfe (1984). Several studies have endorsed the Concern for Appropriateness scale (Johnson, 1989; Wolfe, Lennox, \& Cutler, 1986; Wolfe, Welch, Lennox, \& Cutler, 1985). This leads to the study's third hypothesis:

$\mathrm{H}_{3}$ : Groups with lower levels of communicated disagreements about a perceived majority opinion are more likely to commit groupthink.

One way for group members to communicate disagreements is through asking questions. According to Leighter and Black (2010), group members should raise questions during group meetings for several purposes, including meeting the goal of the group, achieving clarity, helping to structure the conversation, and adding to information that does not tell the entire story. When answers are not available, raising questions is a valuable and effective communication resource, and it may even be a necessary aspect of group discussions and communication (Leighter \& Black, 2010). This relates to conformity and self-censorship, as members of groups must feel comfortable to either question a choice or seek clarification.

\section{Concurrence Seeking}

A key factor in the groupthink phenomenon is the emergence of "mindguards," which are individuals who work and communicate in a way to protect the group leader or the preferred group decision from others. The presence and activity of mindguards represents the notion of group concurrence seeking. Chapman (2006) said that concurrence seeking in groups is the tendency toward convergence and mutual agreement in problem-solving. Groupthink is the term used to describe a situation where concurrence seeking emerges before a problem or proposed solution has been sufficiently 
analyzed or evaluated. According to Longley and Pruitt (1980), the term groupthink is appropriate only when concurrence seeking within a group emerges prematurely, thus decreasing thinking and discussion, and increasing the possibility of a poor decision outcome. McCauley (1989) said that the experience of concurrence seeking in groups differs as individual confidence in the decision favored by the group changes. McCauley also observed evidence that group members may suppress their own doubts about a group decision even if it is actually the best choice. Concurrence seeking seems to produce compliance in groups (Henningsen et al., 2006). Additionally, McCauley showed that concurrence seeking appears to be independent of individual endorsement of a decision. Concurrence seeking can occur when individuals strongly believe in a decision or when individuals are uncertain about a decision as long as there is pressure on group members to favor a course of action. When members of a group are confident that the decision favored by the group is the right decision, they may be unlikely to notice pressures that encourage them to agree with the group's choice (Henningsen et al., 2006). Being unaware of structures causing a group member to self-censor can be just as dangerous as the person realizing what is happening, because they will never have the chance to address the faulty process trapping the group.

The groupthink symptoms of illusion of morality, illusion of invulnerability, and a perception of group consensus all can occur when concurrence seeking behavior are perceived as reflecting a group confidence in the preferred group decision. Group members with little doubt about the choice favored by the group, who also receive feedback from other group members favoring the decision, will be more prone to view themselves as invulnerable and moral than those who have concerns about the group's 
choice. According to Henningsen et al. (2006), the more confidence in a decision instilled, the less susceptible to failure or moral challenges the decision can seem, and the more likely others in the group can seem to agree with the decision. Pressures of concurrence reinforce and strengthen an individual's acceptance of the group's decision.

When group members have their doubts about a position clearly favored by the group, they can become more cognizant of the communicative pressures on them to go along with the group's favored choice. In cases like this, pressures of concurrence can be more noticeable because they will work against the individual expressing their doubts or concerns. These pressures will act to promote compliance with the group's decision (Henningsen et al., 2006). When faced with pressures of concurrence seeking, members of groups should find it more difficult to challenge the group's decision. Symptoms such as pressure to conform and mindguards reflect recognition of a group's pressure to concur, and self-censorship reflects recognition of a group's pressures against dissenters (Henningsen et al., 2006). Additionally, the pressure one faces to go along with the group's choice can create uneasiness within group members who simply comply. This uneasiness and the perception that what the group is doing may not be the best decision can lead to group members to think people outside of the group will judge them more harshly. This leads to the study's next hypothesis:

$\mathrm{H}_{4}$ : Groups whose members communicate higher levels of consensus are more prone to commit groupthink.

\section{Anxiety}

Anxiety follows concurrence seeking because groups sometime use concurrence seeking to help each other, or the group as a whole, deal with high levels of anxiety or 
stress. Janis (1972) theorized that groupthink emerged when groups faced a decision task in a provocative situational context involving a moral dilemma or high risk of material losses. Such situations are stressful, meaning that they make the decision makers anxious and fearful of not being able to cope adequately. According to Janis (1982), the stress in situations like these is intensified when the group has failed previously. From Janis' perspective, this group anxiety relates to concurrence seeking and cohesiveness since concurrence seeking is a way of searching for and providing mutual support to help group members cope with their anxiety and other emotions. Additionally, this stress-reducing tendency is more likely in groups that are highly cohesive.

The antecedent condition of the provocative situational context, which produces stress and anxiety, has received little attention from researchers. Given its importance in the original groupthink model, this is a surprising. Callaway et al. (1985) found support for the hypothesis that concurrence seeking is a stress-reducing process and is not moderated by the occurrence of decision-making procedures. Turner et al. (1992) manipulated the variables of stress and found more rationalization behaviors in information processing when levels of stress were high. Moorhead et al. (1991) asserted the need of more groupthink studies on stress and anxiety, and Chapman (2006), said, "stress and anxiety have been overlooked in research, leaving a central tenant of the groupthink model untested" (p. 1395). Due to the importance of anxiety in the original groupthink model, it is important to account for it.

Anxiety can affect the communication and process of decision-making groups in a number of ways. According to Chapman (2006), "anxiety is a stress-induced emotion that figures large in the groupthink model" (p. 1396). It involves an unpleasant emotional 
state in anticipation of exposure to danger or threat. Anxiety is a continuous feeling of low intensity, having much in common with fear, but with an orientation to future problems rather than immediate threat or harm (English \& English, 1958). Anxiety appears to have a damaging effect on decision makers by affecting the ways in which they process information. Generally, information processing is poorer under negative affect. Next, anxiety may cause a tendency toward excessive risk taking in some situations. Lastly, anxiety can divert attention away from the problem at hand as the reduction of anxiety operates as an implicit motivator, where decision makers become more concerned with reducing the feelings of anxiety, than with finding the best solution to the current problem (Chapman, 2006). When a group is more concerned with reducing their feelings of anxiety as opposed to focusing on making the best decision, groupthink become a very real and looming possibility.

Anxiety, coupled with negative emotions, puts group decision makers in a difficult situation. Research on negative emotions indicates that being in this state typically has a damaging effect on the abilities of decision makers and their communication (Chapman, 2006). Mittal and Ross (1998) said that people in a negative emotional state process information more systematically, while those in a positive state do it more strategically. Overall, the quality of decisions made in a positive mood state is better. According to Garling, Biel, and Gustafsson (1998), environmental uncertainty is one factor that stimulates stress and anxiety. Environmental factors on uncertainty, such as external pressure on the group from outsiders, relates to the idea of a provocative situational context in the original groupthink model. 
When splitting or decreasing someone's resources and thinking due to anxiety, their ability to make an effective decision and communicate as such is tarnished. Heightened levels of stress interfere with optimal human functioning, as stress creates an imbalance between environmental demands and an individual's resources to cope (Chapman, 2006). Evans and Cohen (1987) said that people generally seek to reduce or minimize uncertainty and prefer environments that are more predictable and controllable. According to Leon and Revelle (1985), the efforts to reduce uncertainty interfere with or may limit the full capacity for cognitive functioning. An example of this would be an increase in errors on cognitive tasks.

One theory that helps explain the role of anxiety in groupthink is decision conflict theory. Janis and Mann (1977) proposed a "decision conflict theory" concerning the effects of stress on information processing. This theory contends that decision makers, while under stress, resort to "hypervigilant" strategies for information processing. These communicative strategies become representative of frantic searches for a solution, a failure to consider all alternatives, and disorganization and rapid shifting among possible solutions. Baradell and Klein (1993) supported decision conflict theory when they investigated the effects of anxiety on the quality of decision-making performance. Naturally occurring life stressors, such as undesirable life events or daily hassles, can produce automatic reactions that group members perceive as anxiety (Chapman, 2006). These kinds of reactions demand attention, leaving group members with less capacity to cope with the task, which could ultimately result in impaired decision-making.

Related to feelings of anxiety is the concept of mood. Mittal and Ross (1998) said that people in a positive mood state tend to be less likely to take risks, and that they tend 
to be more against risk taking when the decision is framed as a potential gain. On the other side, people under negative affect are more likely to take risks than those in a neutral state (Mano, 1992, 1994). The "mood maintenance hypothesis" serves as a theoretical explanation for the effects of emotion on risk taking in decision-making groups. According to Isen and Patrick (1983), this suggests that decision makers are motivated to manage their mood state. Those in a positive mood state want to stay that way and avoid risk taking, because failure could induce a mood change. However, people under negative affect are motivated to feel better and are therefore prepared to take risks and communicate as such (Kuvaas \& Kaufmann, 2004; Mittal \& Ross, 1998). In cases of groupthink, the increased chance of risk taking can cause a group not to consider fully possible alternative or consequences of their decision.

Being preoccupied with one's anxiety clearly has negative consequences concerning group decision-making. According to Carlson and Hatfield (1992), "anxiety elicits a defensive response that is often at the cost of considerable self-deception and loss of contact with reality" (p. 33). The defensive response, according to Rycroft (1968), has three modes: controlling one's feelings or those of others, denying the reality of the threat, and seeking an escape from the situation. These communicative responses relate to the groupthink concepts of concurrence seeking, mindguarding, minimization of outsiders, and a sense of invulnerability. Chapman (2006) said that "the anxiety reduction process, which involves engaging in protective modes and defense mechanisms, is a distraction that lowers the chances of a sound choice being made" (p. 1398). Overall, there is enough evidence to support the idea that decision makers tend to be less attentive when they are anxious. This leads to the present study's fifth hypothesis: 
$\mathrm{H}_{5}$ : Groups whose members communicate experiencing high amounts of anxiety or stress will be more likely to commit groupthink.

In sum, when under negative effect, people are not as strategic in the way they gather and evaluate information; therefore, they become inclined toward making riskier decisions. Chapman (2006) characterized these tendencies in the groupthink model as the symptoms of defective decision-making, including incomplete surveying of alternatives, selective bias, and the failure to examine risks. Under negative effect, decision makers also divide their efforts between making the choice and managing their mood state, increasing the possibility of a poorer outcome.

\section{Collective Efficacy}

Collective efficacy is the circumstance in which a group can begin to become over-confident with its decision and become complacent with its communication and decision-making process. In a newly proposed groupthink model, Whyte (1998) suggested that the symptoms of groupthink are due to overconfidence, or an excessive level of collective efficacy. Whyte's view draws on the notion of decision framing as people respond differently to problems framed in terms of perceived losses, as compared to those framed as perceived gains. People tend to be more opposed to risk in situations involving gains, but when the situation is described as leading to potential losses, they are more risk-seeking (Whyte, 1998). According to Whyte, framing effects lead to riskseeking in groups where perceptions of collective efficacy exceed actual capacity, or when a strong "can do" attitude causes groups to take excessive risks to avoid the possible loss of a desired outcome. 
Collective efficacy as a concept is derived from the notion of perceived selfefficacy (Bandura, 1986), which is a key idea in Bandura's $(1977,1986)$ social cognitive theory. Self-efficacy refers to a judgment about one's capability to perform a specific task. It is task-specific self-confidence. Bandura (1986) describes self-efficacy as "people's judgments of their own abilities to organize and execute courses of action required to attain a desired performance. It is concerned not with the skills one has, but with the evaluations of what one can do" (p. 319). Bandura $(1982,1986)$ has suggested that the belief of efficacy extends to groups, or even nations. Bandura (1986) referred to group member's beliefs that "they can solve their problems and improve their lives through concerted effort" (p. 449). Bandura (1997) defined perceived collective efficacy as "a group's belief in their joined efforts to organize and execute the courses of action required to reach their goals" (p. 477). Therefore, group or collective efficacy is a shared belief about the group's ability to successfully perform a task.

Collective efficacy affects communication and the group decision-making process in terms of goal setting, the amount of effort they use, and copying behaviors. Bandura (1997) says that perceptions of collective efficacy:

Influence the type of future groups seek to achieve, how they manage their resources, the plans and strategies they construct, how much effort they put into their group endeavor, their staying power when collective efforts fail to produce quick results or encounter forcible opposition, and their vulnerability to discouragement. (p. 478)

Positively related to perceptions of collective efficacy is group performance (Earley, 1993; Hodges \& Caron, 1992; Prussia \& Kinicki, 1996; Riggs, Warka, Babasa, 
Betancourt, \& Hooker, 1994). The more positive people's judgments of their collective efficacy are, the more they can accomplish.

Although collective efficacy has its benefits, the risks of such patterns cannot be ignored, especially when it comes to groupthink. Perceived personal and collective efficacy may normally be desirable, "but there are circumstances in which this assumption is questionable" (Whyte, 1998, p. 189). For example, efficacy beliefs may be hazardous to hold in situations where an individual or group initiates failing courses of action. According to Staw and Ross (1987), there is a well-documented bias toward staying the course in such circumstances, even when this may make things worse. Whyte, Saks, and Hook (1997) showed that there is a tendency to escalate commitment to a losing course of action, at least at the individual level of analysis, by increasing strong efficacy beliefs. Both forms of efficacy perceptions affect the escalation tendency because both perceived self and collective efficacy influence staying power when individual and group efforts fail to produce results (Whyte, 1998). When a group communicates more commitment to a plan or decision that is incorrect without exploring other options or allowing for dissenting opinions, groupthink is likely occurring. This leads to the study's sixth hypothesis:

$\mathrm{H}_{6}$ : Groups whose members communicate noticeably higher levels of perceived collective efficacy will be more likely to commit groupthink.

Perceived collective efficacy may be problematic when it becomes too high, resulting in overconfidence and ultimately poor performance. High collective efficacy seems to be a positive development, but such conditions do not necessarily foster learning and high performance. Consistent prior success induces high self-efficacy (Bandura \& 
Jourden, 1991), but also induces groupthink concepts of overconfidence, complacency, and decreased search and attention (Lindsley, Brass, \& Thomas, 1995; Sitkin, 1992). The development of upward spirals of collective efficacy might be prolonged and aggravated through groupthink symptoms such as collective rationalizations, self-censorship, and an illusion of unanimity.

\section{Hidden Profiles}

Deliberation can be defined as involving free, equal, and respectful discussion among group members who collaborate in analyzing an issue or situation and aim to come to a "rationally motivated consensus" (Cohen, 1997, p. 74). Ryfe (2005) said that the way in which problems are collectively addressed is the key to successful deliberation. Groups will likely talk their way out of deliberating, as they instead will "hunker down" to do the difficult job of sifting through the various choices and decisions that lie ahead of them. Ryfe added that successful deliberation not only helps groups to evaluate their choices, but also provides the cultural glue that keeps them engaged in the task. Successful deliberation is reliant upon everyone in the group sharing all of the information about a given problem they possess. However, members of groups do not always communicate all of the information they possess during discussions. This failure to communicate information often can result in poor or suboptimal decision-making. According to Bonito, DeCamp, and Ruppel (2008), the fundamental problem is that shared information is typically discussed more frequently during discussions than unique information is. As a result, group outcomes typically suffer. Research has shown that groups tend to perform poorly or make bad decisions largely because members of the group do not always communicate unique information, and when unique information is 
contributed, it often fails to influence the group or be recognized and treated as important (Stasser \& Birchmeier, 2003; Stasser \& Titus, 2003). This can cause a cycle of selfcensorship, where a group member realizes their information or input becomes ignored, and they might stop providing information that may be helpful.

If group members do not communicate all of the information in their possession, they could be contributing to the occurrence of groupthink by not creating discussion of alternative ideas. According to Henningsen et al. (2006), a "hidden profile" is created when decision-relevant information communicated to others favors a suboptimal decision, but information held privately by individuals instead favors a better choice. Stasser and Titus (1985) found that groups tend not to make the best decision, but instead choose the group majority's initially favored option. The hidden profile problem is very similar to the issue of compliance pressure in groupthink (Henningsen et al., 2006). Group members can hold information that contradicts the group's decision preference, but there is a tendency for that information to not be communicated due to pressures of compliance (e.g., Cruz, Boster, \& Rodriquez, 1997). Additionally, raising information that is inconsistent with the group's pre-discussion preferences is often treated as less important and as less credible than information that is consistent with the group's preference (Greitmeyer \& Schulz-Hardt, 2003; Henningsen \& Henningsen, 2003). This relates to the idea discussed earlier of a group member beginning to feel ignored or not respected, causing them to self-censor.

Group confidence, or efficacy, is one issue related with hidden profiles that can have a profound effect on how the group conducts itself and goes about making its decision. Henningsen et al. (2006) found that group members with full information 
communicate a greater confidence in the group's decision than members in hidden profile groups. What this means is that hidden profile groups have less confidence than groups with full information; likely because they know they do not have all of the information and, therefore, do not become overconfident or think they are invulnerable. Conversely, groups with more information are more confident in their choice, creating an illusion of invulnerability, which can make them more likely to fall victim to groupthink or suffer from a disastrous choice. Henningsen et al. also concluded that hidden profile groups had more pressure to conform and were more likely to experience mindguards than groups with full information. Additionally, members of hidden profile groups felt that they engaged in more self-censoring behaviors and were more likely to have biased perceptions of out-groups. On the other hand, groups with full information had higher perceptions of invulnerability, as well as high perceptions of morality and consensus. Thus, the conditions surrounding hidden profile groups work to promote the chances of groupthink, which leads to the study's seventh hypothesis:

$\mathrm{H}_{7}$ : As the number of members in a group with hidden profiles (privately held information) increases, the propensity to commit groupthink also increases.

\section{Trust}

Trust within teams is a function of other team members' perceived ability and integrity, and its main function is to provide synergistic relations, or "teamthink" (Manz \& Neck, 1995). Trust preforms this important function by activating appropriate social processes, such as: broad and flexible role definition, intensive social relations, high confidence in others, help-seeking behavior, a free exchange of information, giving priority to team objectives or needs, and high commitment and solidarity (Jones \& 
George, 1998). Because of this, trust is a required condition for teamwork and effective communication.

However, too much trust can be risky or could result in groupthink, as group members begin to self-censor as to not deviate from the perceived consensus (Erdem, 2003). Additionally, the team can apply social pressures to those who argue or disagree with the team's shared beliefs. Together, they try to rationalize decisions within their values and norms, and in all situations, pursue agreement. According to Manz and Neck (1995), when teams do not discuss or sufficiently analyze alternative decisions or ways of thinking due to trust, they increase the possibility of wrong or ineffective decisionmaking. This understanding of too much trust becoming a negative concept in group decision-making leads to the study's eighth hypothesis:

$\mathrm{H}_{8}$ : Groups whose members communicate higher levels of trust will be more likely to commit groupthink.

Finding the appropriate amount of trust is something that does not come easy to groups. According to Erdem (2003), the ideal level of trust suggests realizing both the positive aspects of trust and distrust simultaneously, and eliminating or minimizing the negative aspects of both constructs. At the optimal level, team members trust each other and express their views freely, behave altruistically, share information and resources and display good, intentional behavior, but must "also exhibit the signs of distrust in searching for diversity, defending alternative solutions, being less rigid, retaining a degree of skepticism, and inquiring and criticizing" (Erdem, 2003, p. 230). In sum, then, too much trust can negatively influence team performance, and in order to maximize 
performance, teams should exhibit critical inquiry skills and constructive criticism adding to a supportive understanding.

\section{Predicting Groupthink}

A major focus of this study is to show that the combination of these predictor variables can work together to put a group's decision-making process in peril, and introduce an increased risk of making a disastrous decision or causing a nagging problem. However, also worth of discovery is which variables best predict groupthink. This leads to the study's final research question:

$\mathrm{RQ}_{3}$ : Which predictor variables (highly cohesive groups, promotional leadership, conformity, concurrence seeking, anxiety, collective efficacy, hidden profiles, and trust) are the strongest predictors of the groupthink phenomenon? 


\section{CHAPTER II}

\section{METHOD}

One reason for the lack of comprehensive empirical research on groupthink could be the lack of appropriate instruments for measuring groupthink or its variables. The catch-22 involved, and the potential reason these efforts have not been completed before, is that groupthink is very tough to understand or predict looking ahead, without the use of retrospective sensemaking. Even with the appropriate antecedents of groupthink in place, and with similar communication processes as the errors made by groupthink groups, groupthink does not always occur. Simply put, what appears to cause groupthink does not always cause it. The disastrous outcomes are almost due to random chance. However, if an instrument can be developed to consistently and accurately measure the variables associated with groupthink, that still represents a positive step in understanding the group communication process and how to make the best of the these situations.

\section{Participants}

The research participants used in this study to develop a scale to more effectively measure a group's propensity toward the phenomenon of groupthink included university faculty, staff, and students, as well as working professionals in the community, and coaches in the community. Additionally, participants included those who had access to the School of Communication's Research Pool webpage over the course of both the fall and the spring semesters. All students enrolled in a communication course at the 
university were granted access to the research pool in which the survey was located. After completion of the survey, some students received the opportunity to earn extra credit for their participation at the discretion of their instructor. Participation in the study was voluntary, and the criteria for participating in the study was that participants must have turned 18 years of age at the time of the study and must have been involved with one decision-making group experience within the last year.

The reason for the research participants was to create a large enough sample to establish validity for the survey instrument, and to cast a wide net at different professional sites to create a more diverse and representative sample. An initial estimate of 250-350 participants was targeted, with permission for 500 participants granted by the University's institutional review board. When it comes to the campus community, a randomized list of 470 faculty, staff, and coaches, balanced by males and females, was utilized. Overall, 300 faculty members (150 males and 150 females), 100 staff members (50 males and 50 females), and 70 coaches or athletics personnel (50 males and 20 females) were contacted. When it comes to the participants at professional organizations, a network sample was used, meaning that a contact person at each organization was asked to forward the survey to others within their organization. The organizations contacted included the Normal CornBelters, the Bloomington Thunder, Beer Nuts Incorporated, State Farm Insurance, local rotary clubs, and the athletic departments at Illinois State University, Illinois Wesleyan University, and Heartland Community College. Additionally, working professionals were accessed by utilizing the CRTNET listserv, and through social media access, including a mention on the Uptown Normal Facebook page. The reason for collecting responses from both student and working 
professional populations was to make reasonable comparisons and claims between the two groups.

\section{Descriptive Statistics}

A total of 253 participants voluntarily completed the survey. Of those participants, 137 were students $(54.2 \%)$ and 116 were working adults (45.8\%). Participants represented 17 different types of groups, with a mean group size of 9.84 members $(S D=15.56)$. Out of the 210 participants who completed the demographics section, 142 participants were females (67.6\%), 67 were males (31.9\%), and one selected other $(0.5 \%)$. In terms of age, participants fell within the range of $18-83$ years of age $(M$ $=44, S D=12.03)$. Overall, respondents predominately identified themselves as Caucasian $(n=181,86.2 \%)$, followed by Hispanic $(n=10,4.8 \%)$, African American $(n=$ 7, 3.3\%), Bi-racial/Mixed $(n=4 ; 1.9 \%)$, Asian/Pacific Islander $(n=4,1.9 \%)$, Native American $(n=2,1.0 \%)$, and other $(n=2 ; 1.0 \%)$. Lastly, $225(89.3 \%)$ participants reported that their group met mostly face-to-face, compared to $27(10.7 \%)$ who said their group met mostly through virtual channels.

\section{Research Design and Procedures}

The University's Institutional Review Board approved all procedures. To answer the research questions and each of the study's hypotheses, a quantitative survey questionnaire was administered through a secure web-based software program called SelectSurvey. Participants were instructed in the e-mail invitation to click on a hyperlink taking them to a web page that explained the nature of the study and informed them of their rights as research participants. The participants indicated their consent to take part in the study by clicking another hyperlink at the bottom of the webpage that took them to 
the online survey. Responses were based upon a previous group experience where a bad or disastrous decision was made; therefore, retrospective self-report data was collected. Participants were also asked to provide group and individual demographic information in order to frame responses and to collect aggregate characteristics.

\section{Measures}

The survey items were developed specifically for this study. The scales examine variables associated with groupthink. The survey item pool was constructed through a comprehensive literature review and evaluation of the possible variable predictors of groupthink. The review of literature included an SSCI (or Impact) analysis on Janis' (1972) original work on groupthink via the Web of Science database. This allows for backtracking and identifying every citation of a particular source across all fields to account for missing literature, additional scales, and to make sure no outstanding gaps on research within a topic remain unmentioned. Of particular interest were the sources that cited Janis (1972), and had then been cited themselves over 100 times. By identifying all of the prominent groupthink studies with the help of the SSCI analysis, the independent variables and corresponding scales were finalized.

The eight scales were entitled Highly Cohesive (9 items), Promotional Leadership (11 items), Conformity (12 items), Concurrence Seeking (13 items), Anxiety (12 items), Collective Efficacy (12 items), Hidden Profiles (9 items), and Trust (10 items). The survey items were arranged on a 5-point Likert scale, asking participants to indicate their level of agreement with the items, from 1 (strongly disagree) to 5 (strongly agree). To control for a variable potentially not applying to a particular group, the respondent would indicate "strongly disagree" with a statement, simply showing that one did not believe the 
statement to be true for their group. For example, within the predictor variable of promotional leadership, if a group had zero or multiple leaders, a participant would likely "strongly disagree" with the items accessing this predictor.

Example questions from the Highly Cohesive scale included: "Our group communicated a high degree of shared interest," "Our group focused more on staying together than on making the best decision," and "Members of the group indicated they shared many of the same values." Examples from the Promotional Leadership scale included: "Our group leader encouraged others to express their own ideas," "Our leader stated her/his preference up front," and "Our group leader pushed her/his decision over others." Examples for the Conformity scale included: "I often agreed openly with the group's decision, even if I disagreed privately," "I often kept my opinions to myself," and "Everyone in the group had a voice." The Concurrence Seeking scale had questions like "I felt pressure from the group to not rock the boat," "Some group members prevented others from expressing opposing points of view," and "Our group promoted the importance of reaching a consensus."

Examples for the Anxiety scale included: "Our group's decision involved risk," "Our group had failed previously, which added to our stress," "Our group provided support to help members cope with expressed stress," and "Our group tried to escape from the stressful situation as quickly as we could." The collective efficacy scale had questions like: "Our group expressed confidence with our decision," "Our group became complacent with our decision-making process," and "Our group believed in its ability to execute a plan to reach our goals." The Hidden Profiles scale included questions such as: "When information that was inconsistent with the majority opinion was brought up, it 
was viewed as less important than information consistent with the majority opinion," "Our group really only discussed information that was common to everyone," and "When unique information was contributed, it was recognized and treated as important." Lastly, examples from the Trust scale included: "There was a mutual sense of trust within the group," "There was too much trust within the group," "I often looked to my fellow group members for help," and "I felt free to exchange information about myself with our group."

In the end, 88 scaled items were included on the survey instrument along with 12 items requesting information about the group communication and decision, as well as various group and individual demographic questions. For example, one of these demographic items asked participants to identify if their group met mostly face-to-face or virtually, allowing for a comparison of such responses. See the attached Appendix for the full survey instrument.

\section{Data Analysis}

\section{Estimates of Reliability}

Following the collection of data, Cronbach's alpha coefficient reliability estimates were calculated using the Statistical Package for the Social Sciences (SPSS). While an alpha of .65 to .70 is considered minimally acceptable, a respectable coefficient alpha for a scale is .70 to .80 , a very good alpha is .80 to .90 , and an excellent alpha is .90 or above (DeVellis, 2003). According to DeVellis, redundancy of content among items is one means of improving the internal consistency reliability of a scale.

The three-item Highly Cohesive scale produced an alpha reliability coefficient of .82 , thus indicating very good reliability for the scale. The eight-item Promotional 
Leadership scale produced a respectable reliability for the overall scale $(\alpha=.79)$, while the five-item Leader Dogmatism $(\alpha=.81)$ and three-item Leader Immediacy subscales $(\alpha$ $=.82$ ) each had very good reliability. The seven-item Conformity scale produced very good reliability $(\alpha=.82)$, as well as for the five-item Self-Censorship $(\alpha=.83)$ and twoitem Free Discussion subscales $(\alpha=.81)$. The eight-item Concurrence Seeking scale produced very good reliability $(\alpha=.82)$ as well as very good reliability and acceptable reliabilities for the six-item Mindguarding $(\alpha=.85)$ and two-item Reservation Encouragement subscales $(\alpha=.66)$ respectfully. Both the five-item Anxiety scale $(\alpha=$ .87) and seven-item Collective Efficacy scale $(\alpha=.87)$ produced very good reliabilities. The three-item Hidden Profiles scale produced a respectable reliability for the overall scale $(\alpha=.78)$. Lastly, the eight-item Trust scale produced very good reliability for the overall scale $(\alpha=.80)$, as well as very good and respectable reliabilities for the six-item Trusting Culture $(\alpha=.88)$ and two-item Overly Trusting subscales $(\alpha=.72)$ respectfully. Thus, with the exception of the Promotional Leadership and Hidden Profiles scales, and the Reservation Encouragement and Overly Trusting subscales, all other scales and subscales had very good alpha reliability estimates. Table 1 shows the 12 composite variables in the survey instrument along with alpha reliability coefficients and dimensionality for each scale. 
Table 1

Composite Variables Measured in the Survey Instrument

\begin{tabular}{lll}
\hline Scale & Composite Variable & $\alpha$ \\
\hline Highly Cohesive & Highly Cohesive & .82 \\
Promotional Leadership & & .79 \\
& Leader Dogmatism & .81 \\
Conformity & Leader Immediacy & .82 \\
& & .82 \\
Concurrence Seeking & Self-Censorship & .83 \\
& Free Discussion & .81 \\
& & .82 \\
Anxiety & Mindguarding & .85 \\
Collective Efficacy & Reservation Encouragement & .66 \\
Hidden Profiles & Anxiety & .87 \\
Trust & Collective Efficacy & .87 \\
& Hidden Profiles & .78 \\
& & .80 \\
& Trusting Culture & .88 \\
\hline
\end{tabular}

Note. The 12 composite variables were measured by eight scales. Four of the scales consisted of two factors, while the other four scales consisted of single factors. Alpha levels are reported for overall scales as well as for each factor in multidimensional scales.

\section{Reverse Coding of Items}

Due to the reverse polarity of item wording, several items were reverse coded prior to conducting factor analysis and reliability estimates. Specifically, items 11, 13, 15, $17,19,25,29,30,33,35,36,37,44,46,49,55,75,77,78,82$, and 87 from the original survey were reverse coded (see Appendix for item wording). Reverse coding was conducted in accordance with making the higher numeric response to an item indicate that groupthink was more likely. 


\section{Exploratory Factor Analysis}

Following the collection of data in the online survey, a series of exploratory factor analysis (EFA) procedures were run to detect underlying constructs within the groupthink scale. The criteria for acceptable factor loadings was .6 or above on the primary factor and .4 or below on the secondary factors. Due to the suspected relationship of survey items to scaled variables, survey items were grouped based upon their association with particular variables. Thus, the use of EFA maintained the separation of variables while still permitting examination of potential factors within each variable. A data reduction process was also employed during the EFA of the eight scales, identifying factors within the eight scales and eliminating survey items that did not adequately load onto a factor. After eliminating particular survey items, new EFA procedures were conducted until a desirable final factor solution was reached. As the process of data reduction proceeded, the item with the lowest primary factor loading that did not meet the $60 / 40$ criteria was removed from the solution and a new EFA procedure was conducted. These EFAs and scale reliability tests determine the predictor variables that help give insight into the criterion variable of groupthink, thereby addressing the first two research questions. Groupthink was measured by asking participants to answer the survey questions with a group or team experience in mind where the worst decision occurred. At the end of the survey, participants were given a definition of groupthink and then asked how many times they believe groupthink occurred in their group as well as how disastrous they believed the decision to be; thus, resulting in two criterion variables.

To meet the assumptions of factor analysis, the Kaiser-Meyer-Olkin (KMO) coefficient, a measure of sampling accuracy, should be in the high .8s and the Bartlett's 
test of sphericity should be significant (Mertler \& Vannatta, 2005). Next, factor structure was determined by analyzing several criteria for selecting items that cluster together into factors (Mertler \& Vannatta, 2005). Components accounting for 70\% or more of the total variability should be retained (Mertler \& Vannatta, 2005). Additionally, eigenvalue scores, a visual inspection of the scree plot, and the rotated factor matrix helped to determine how many factors to retain. According to Kaiser's rule, only factors with eigenvalues greater than 1 should be retained (Mertler \& Vannatta, 2005).

During scale development, it is important that survey items be subjected to factor analysis to either identify clusters of items or confirm the suspected groupings of items and underlying constructs. Scale development is aided by the use of factor analysis (DeVellis, 2003), which is a technique that groups items, or variables, that measure a common construct (Mertler \& Vannatta, 2005). However, factor analysis does not require independent and dependent variables to be distinguished (Meyers, Gamst, \& Guarino, 2006). Lastly, sample size and sampling procedures are important considerations during scale development. For instance, according to Meyers et al., the recommended sample size is a ratio of 10 participants for every variable, with at least 200 participants. Importantly, though, a larger number of variables permit the relaxation of this ratio (Meyers et al., 2006).

\section{Multiple Linear Regression}

To further measure the eight independent variables and answer the corresponding hypotheses as well as RQ3, two multiple linear regressions were employed. The level of significance, or alpha, was set to .05 in agreement with common practices, and no changes were made to adjust alpha to a more conservative level given that the results of 
the study do not endanger groups or individuals in any direct way. The argument for using multiple linear regression lies in the interrelationship among variables as found in the real world. Researchers generally accept the use of multiple predictor variables because the procedure is more representative of "how the world works" than simple regression, and can be used for both explanatory and predictive purposes (Meyers et al., 2006, p. 147). Additionally, multiple regression better reflects the multiple causes of events such as the criterion variable, as compared to simple regression or other procedures that isolate single causes of events (Miles \& Shevlin, 2001). According to Meyers et al., research that seeks to predict one variable based upon a combination of several other variables justifies a regression design. Lastly, the variables included in the regression model should, ideally, be based on as much empirical and theoretical evidence as possible (Meyers et al., 2006; Miles \& Shevlin, 2001).

Multiple linear regression analysis uses multiple predictor, or independent, variables to predict the scores on a single quantitatively measured criterion variable, which is commonly called the dependent variable (Hinkle, Wiersma, \& Jurs, 2003; Meyers et al., 2006). According to Miles and Shevlin (2001), the dependent variable in a regression model should be based on continuous data on either an interval or a ratio scale. This study meets the criterion set by Miles and Shevlin, showing that summed scales of Likert items can produce continuous data on an interval level (DeVellis, 2003). According to Hinkle et al., the multiple $R$ value produced by the multiple linear regression procedure accounts for the linear combination of the multiple predictor variables. The goal in multiple linear regression is to find a set of predictor variables that are each highly correlated with the dependent variable, but not with each other, to 
maximize the variance accounted for by the regression model (Hinkle et al., 2003; Meyers et al., 2006). As Hinkle et al. stated, "an ideal set of predictor variables will account for different proportions of variance in the criterion variable while having low correlations among themselves" (p. 472). 


\section{CHAPTER III \\ FACTOR ANALYSIS}

To validate the survey measures, a series of EFA procedures employing principle axis factoring with varimax rotation were run to test for underlying constructs within each independent variable scale, to identify factors within the eight scales, and eliminate survey items that did not adequately load onto a factor. Varimax rotation was employed because rotating factor solutions allows for more interpretable results (Mertler \& Vannatta, 2005). As particular survey items were eliminated due to poor factor loadings, new EFA procedures were conducted until a desirable final factor solution was reached. In total, the iterative EFA process eliminated 39 original items from the instrument because of poor factor loadings.

\section{Highly Cohesive}

For the Highly Cohesive scale, original items 13, 12, 8, 9, 10, and 11 were eliminated through iterative EFA procedures. The final EFA procedure produced an acceptable single-factor solution. Both the KMO measure (.692) and Bartlett's test $\left[\chi^{2}=\right.$ $259.216(3), p<.001]$ were acceptable. The factor explained $62.117 \%$ of the variance and had an eigenvalue of 2.220. The Highly Cohesive scale consisted of three items and produced a very good alpha coefficient reliability of .824 for the scale. See Table 2 for factor loadings. 
Table 2

Factor Loadings for Highly Cohesive Scale

\begin{tabular}{|c|c|}
\hline Survey Item & Highly Cohesive \\
\hline 6. Our group communicated a high degree of shared interest. & .896 \\
\hline 7. I would consider our group to be highly cohesive. & .781 \\
\hline $\begin{array}{l}\text { 14. Members of the group indicated they shared many of the same } \\
\text { values. }\end{array}$ & .672 \\
\hline Eigenvalue & 2.220 \\
\hline$\%$ of Variance & 62.117 \\
\hline Cronbach's Alpha & .824 \\
\hline
\end{tabular}

Note. Underlined factor coefficients show acceptable factor loadings.

\section{Promotional Leadership}

For the Promotional Leadership scale, original items 15, 18, and 16 were eliminated, while the final EFA procedure produced an acceptable two-factor solution. Both the KMO measure (.764) and the Bartlett's test $\left[\chi^{2}=710.186(28), p<.001\right]$ were acceptable. The two-factor solution, consisting of five items and three items respectively, explained 54.729\% of the variance in the overall scale. The first factor accounted for $36.366 \%$ of the total variance with an eigenvalue of 3.349, and the second factor explained $18.363 \%$ of the total variance with a 1.919 eigenvalue. The first factor, labeled as Leader Dogmatism, consisted of five items related to the group leader's agenda, and the second factor, labeled as Leader Immediacy, consisted of three items related to leader's approachability. The two-factor solution for the eight-item scale produced a respectable overall alpha coefficient of .796. The alpha coefficients for the Leader Dogmatism measure (.818) and the Leader Immediacy measure (.822) were both very good reliabilities. See Table 3 for factor loadings. 
Table 3

Factor Loadings for Promotional Leadership Scale

\begin{tabular}{|c|c|c|}
\hline Survey Item & $\begin{array}{c}\text { Leader } \\
\text { Dogmatism }\end{array}$ & $\begin{array}{c}\text { Leader } \\
\text { Immediacy }\end{array}$ \\
\hline $\begin{array}{l}\text { 23. Our group discussed fewer facts because our leader } \\
\text { had already made her/his decision clear. }\end{array}$ & .727 & .192 \\
\hline $\begin{array}{l}\text { 20. Our group leader pushed her/his decision over } \\
\text { others. }\end{array}$ & .692 & .375 \\
\hline $\begin{array}{l}\text { 21. The leader strongly influenced the final group } \\
\text { decision. }\end{array}$ & .686 & .012 \\
\hline $\begin{array}{l}\text { 24. Because of our leader's comments, our group } \\
\text { reached a decision too quickly. }\end{array}$ & .685 & .222 \\
\hline $\begin{array}{l}\text { 22. The group often deferred to the opinions of the } \\
\text { leader. }\end{array}$ & .606 & -.120 \\
\hline $\begin{array}{l}\text { 17. Our group leader encouraged others to express their } \\
\text { own ideas. [Recoded] }\end{array}$ & .074 & .799 \\
\hline 25. Our leader was approachable. [Recoded] & .056 & .771 \\
\hline $\begin{array}{l}\text { 19. Our leader made sure her/his opinion did not hold } \\
\text { more weight than the group's opinion as a whole. } \\
\text { [Recoded] }\end{array}$ & .153 & .746 \\
\hline Eigenvalue & 3.349 & 1.919 \\
\hline$\%$ of Variance & 36.366 & 18.363 \\
\hline Cronbach's Alpha & .818 & .822 \\
\hline
\end{tabular}

Note. Underlined factor coefficients show acceptable factor loadings for the corresponding items and factors.

\section{Conformity}

For the Conformity scale, original items 36, 35, 34, 33, and 37 were eliminated, while the final EFA procedure produced an acceptable two-factor solution. Both the KMO measure (.797) and the Bartlett's test $\left[\chi^{2}=603.949(21), p<.001\right]$ were acceptable. The two-factor solution, consisting of five items and two items respectively, explained $57.653 \%$ of the variance in the overall scale. The first factor accounted for $43.346 \%$ of the total variance with an eigenvalue of 3.466, and the second factor 
explained $14.307 \%$ of the total variance with a 1.358 eigenvalue. The first factor, labeled as Self-Censorship, consisted of five items related to the participant keeping opinions to themselves, and the second factor, labeled as Free Discussion, consisted of two items related to participants' abilities to express opinions and asks questions. The two-factor solution for the seven-item scale produced a very good overall alpha coefficient of .828 . The alpha coefficients for the Self-Censorship measure (.837) and the Free Discussion measure (.819) were both very good reliabilities. See Table 4 for factor loadings.

Table 4

Factor Loadings for Conformity Scale

\begin{tabular}{|c|c|c|}
\hline Survey Item & Self-Censorship & Free Discussion \\
\hline $\begin{array}{l}\text { 31. I often failed to express disagreement with } \\
\text { what someone else said. }\end{array}$ & .734 & .148 \\
\hline $\begin{array}{l}\text { 32. I had doubts about the group's decision, but } \\
\text { did not say anything. }\end{array}$ & .728 & .159 \\
\hline 28. I often kepy my opinions to myself. & .686 & .303 \\
\hline $\begin{array}{l}\text { 26. I often agreed openly with the group's } \\
\text { decision, even if I disagreed privately. }\end{array}$ & .672 & .011 \\
\hline $\begin{array}{l}27 . \text { I felt a pressure to agree with the group's } \\
\text { opinions. }\end{array}$ & .623 & .345 \\
\hline $\begin{array}{l}\text { 29. I felt free to express any conerns I had with } \\
\text { ideas that were proposed. [Recoded] }\end{array}$ & .179 & .828 \\
\hline $\begin{array}{l}\text { 30. I felt comfortable asking questions about a } \\
\text { solution. [Recoded] }\end{array}$ & .152 & .811 \\
\hline Eigenvalue & 3.466 & 1.358 \\
\hline$\%$ of Variance & 43.346 & 14.307 \\
\hline Cronbach's Alpha & .837 & .819 \\
\hline
\end{tabular}

Note. Underlined factor coefficients show acceptable factor loadings for the corresponding items and factors. 


\section{Concurrence Seeking}

For the Concurrence Seeking scale, original items 50, 44, 45, 41, and 48 were eliminated, while the final EFA procedure produced an acceptable two-factor solution. Both the KMO measure (.807) and the Bartlett's test $\left[\chi^{2}=673.457(28), p<.001\right]$ were acceptable. The two-factor solution, consisting of six items and two items respectively, explained 50.959\% of the variance in the overall scale. The first factor accounted for $40.154 \%$ of the total variance with an eigenvalue of 3.698 , and the second factor explained $10.805 \%$ of the total variance with a 1.348 eigenvalue. The first factor, labeled as Mindguarding, consisted of six items related to group members protecting the preferred group decision, and the second factor, labeled as Reservation Encouragement, consisted of two items related to group members encouraging others to express their doubts about decision options. The two-factor solution for the eight-item scale produced a very good overall alpha coefficient of .823 . The alpha coefficients for the Mindguarding measure (.858) and the Reservation Encouragement measure (.664) were very good and acceptable reliabilities, respectively. See Table 5 for factor loadings. 
Table 5

Factor Loadings for Concurrence Seeking Scale

\begin{tabular}{|c|c|c|}
\hline Survey Item & Mindguarding & $\begin{array}{c}\text { Reservation } \\
\text { Encouragement }\end{array}$ \\
\hline $\begin{array}{l}\text { 38. I felt pressure from the group to not "rock the } \\
\text { boat." }\end{array}$ & .774 & .108 \\
\hline $\begin{array}{l}\text { 42. The group pressured members to agree with } \\
\text { each other. }\end{array}$ & .723 & .171 \\
\hline $\begin{array}{l}\text { 40. Members of the group acted as mindguards, } \\
\text { protecting the group leader or preferred group } \\
\text { decision from others. }\end{array}$ & .709 & .049 \\
\hline $\begin{array}{l}\text { 43. As a group, we failed to fully acknowledge the } \\
\text { opinions of those with a particular experise in a } \\
\text { given area. }\end{array}$ & .694 & .118 \\
\hline $\begin{array}{l}\text { 47. Some group members prevented others from } \\
\text { expressing opposing points of view. }\end{array}$ & .655 & .123 \\
\hline $\begin{array}{l}\text { 39. I felt presure to just go along with the group's } \\
\text { preferred decision. }\end{array}$ & .640 & .125 \\
\hline $\begin{array}{l}\text { 49. When I spoke up about any doubts I had, my } \\
\text { fellow group members seriously listened to me. } \\
\text { [Recoded] }\end{array}$ & .238 & .705 \\
\hline $\begin{array}{l}\text { 46. The group encouraged members to express } \\
\text { reservations they had about the group decision } \\
\text { [Recoded] }\end{array}$ & .023 & .698 \\
\hline Eigenvalue & 3.698 & 1.348 \\
\hline$\%$ of Variance & 40.154 & 10.805 \\
\hline Cronbach's Alpha & .858 & .664 \\
\hline
\end{tabular}

Note. Underlined factor coefficients show acceptable factor loadings for the corresponding items and factors.

\section{Anxiety}

For the Anxiety scale, original items 55, 57, 56, 51, 52, 54, and 53 were eliminated through iterative EFA procedures. The final EFA procedure produced an acceptable single-factor solution. Both the KMO measure (.848) and Bartlett's test $\left[\chi^{2}=503.138\right.$ $(10), p<.001]$ were acceptable. The factor explained $57.748 \%$ of the variance and had an 
eigenvalue of 3.305. The Anxiety scale consisted of five items and produced a very good alpha coefficient reliability of .871 for the scale. See Table 6 for factor loadings.

Table 6

Factor Loadings for Anxiety Scale

\begin{tabular}{|c|c|}
\hline Survey Item & Anxiety \\
\hline $\begin{array}{l}\text { 59. Our group failed to consider all possible alternatives to our } \\
\text { decision due to the pressures of expressed stress and anxiety. }\end{array}$ & .805 \\
\hline $\begin{array}{l}\text { 58. Because of our anxiety, our group was frantic in trying to make } \\
\text { a decision. }\end{array}$ & .797 \\
\hline 61. Members of the group became defensive due to expressed stress. & .754 \\
\hline $\begin{array}{l}\text { 60. Our group tried to escape from the stressful situation as quickly } \\
\text { as we could. }\end{array}$ & .748 \\
\hline 62. I felt fear or anxiety over the group's task. & .690 \\
\hline Eigenvalue & $\overline{3.305}$ \\
\hline$\%$ of Variance & 57.748 \\
\hline Cronbach's Alpha & .871 \\
\hline
\end{tabular}

Note. Underlined factor coefficients show acceptable factor loadings.

\section{Collective Efficacy}

For the Collective Efficacy scale, original items 66, 65, 74, 72, and 64 were eliminated through iterative EFA procedures. The final EFA procedure produced an acceptable single-factor solution. Both the KMO measure (.891) and Bartlett's test $\left[\chi^{2}=\right.$ $663.706(21), p<.001]$ were acceptable. The factor explained $50.816 \%$ of the variance and had an eigenvalue of 4.028. The Collective Efficacy scale consisted of seven items and produced a very good alpha coefficient reliability of .876 for the scale. See Table 7 for factor loadings. 
Table 7

Factor Loadings for Collective Efficacy Scale

Survey Item

Collective

Efficacy

68. Our group believed in its ability to execute a plan to reach our goals.

$\underline{.806}$

67. Our group communicated a "can do" attitude.

.786

69. Our group strongly communicated an ability to complete the task at hand.

$\underline{.764}$

70. Our group was not easily discouraged.

.745

73. Our group believed we could solve our own problems if we worked together.

.629

71. Our group "stayed the course," even when things looked bad.

.622

63. Our group expressed confidence with our decision.

Eigenvalue $\quad 4.028$

$\%$ of Variance $\quad 50.816$

Cronbach's Alpha

.876

Note. Underlined factor coefficients show acceptable factor loadings.

\section{Hidden Profiles}

For the Hidden Profiles scale, original items 76, 82, 79, 81, 83, and 80 were eliminated through iterative EFA procedures. The final EFA procedure produced an acceptable single-factor solution. Both the KMO measure (.704) and Bartlett's test $\left[\chi^{2}=\right.$ $178.097(3), p<.001]$ were acceptable. The factor explained $54.535 \%$ of the variance and had an eigenvalue of 2.090. The Hidden Profiles scale consisted of three items and produced a respectable alpha coefficient reliability of .780 for the scale. See Table 8 for factor loadings. 
Table 8

Factor Loadings for Hidden Profiles Scale

\begin{tabular}{|c|c|}
\hline Survey Item & Hidden Profiles \\
\hline $\begin{array}{l}\text { 77. Our group often discussed unique information that not everyone } \\
\text { began the discussion with knowledge of. [Recoded] }\end{array}$ & .756 \\
\hline $\begin{array}{l}\text { 75. Everyone in the group shared all of the information they had } \\
\text { about a particular problem or task. [Recoded] }\end{array}$ & .734 \\
\hline $\begin{array}{l}\text { 78. When unique information was contributed, it was recognized } \\
\text { and treated as important. [Recoded] }\end{array}$ & .726 \\
\hline Eigenvalue & 2.090 \\
\hline$\%$ of Variance & 54.535 \\
\hline Cronbach's Alpha & .780 \\
\hline
\end{tabular}

Note. Underlined factor coefficients show acceptable factor loadings.

\section{Trust}

For the Trust scale, original items 87 and 93 were eliminated, while the final EFA procedure produced an acceptable two-factor solution. Both the KMO measure (.823) and the Bartlett's test $\left[\chi^{2}=768.120(28), p<.001\right]$ were acceptable. The two-factor solution, consisting of six items and two items respectively, explained $58.434 \%$ of the variance in the overall scale. The first factor accounted for $42.592 \%$ of the total variance with an eigenvalue of 3.804 , and the second factor explained $15.842 \%$ of the total variance with a 1.703 eigenvalue. The first factor, labeled as Trusting Culture, consisted of six items related to a supportive and helpful group environment, and the second factor, labeled as Overly Trusting consisted of two items related to group members expressing too much trust. The two-factor solution for the eight-item scale produced a good overall alpha coefficient of .805. The overall alpha coefficients for the Trusting Culture measure (.880) and the Overly Trusting measure (.725) were very good and acceptable reliabilities, respectively. See Table 9 for factor loadings. 
Table 9

Factor Loadings for Trust Scale

\begin{tabular}{|c|c|c|}
\hline Survey Item & Trusting Culture & Overly Trusting \\
\hline 89. Our group's environment was supportive. & .857 & .090 \\
\hline $\begin{array}{l}\text { 84. There was a mutual sense of trust within the } \\
\text { group. }\end{array}$ & .780 & .211 \\
\hline $\begin{array}{l}\text { 90. I had confidence in our group members to } \\
\text { make the right decision. }\end{array}$ & .760 & .012 \\
\hline $\begin{array}{l}\text { 92. I felt free to exchange information about } \\
\text { myself with our group. }\end{array}$ & .755 & -.032 \\
\hline $\begin{array}{l}\text { 91. I often looked to my fellow group members } \\
\text { for help. }\end{array}$ & .666 & 199 \\
\hline 88. Group members expressed their views freely. & .659 & -.280 \\
\hline $\begin{array}{l}\text { 86. No one in the group wanted to break the } \\
\text { feeling of trust by bringing up opposing ideas. }\end{array}$ & -.024 & .773 \\
\hline 85. There was too must trust within the group. & .115 & .725 \\
\hline Eigenvalue & 3.804 & 1.703 \\
\hline$\%$ of Variance & 42.592 & 15.842 \\
\hline Cronbach's Alpha & .880 & .725 \\
\hline
\end{tabular}

Note. Underlined factor coefficients show acceptable factor loadings for the corresponding items and factors.

\section{Summary}

The EFA results support the use of the eight groupthink scales, thus indicating that the scales are able to tap into the variables of interest. Results indicated that the survey was able to be factor analyzed with acceptable to very good reliabilities after eliminating several survey items, thereby answering both research questions one and two. Findings indicate that the survey instrument measures 12 distinct scales and subscales related to predictors of groupthink, and are conceptually consistent with the domain of the variables examined, reflecting the content domain of the scales, and demonstrating good content validity (DeVellis, 2003; Frey, Botan, \& Kreps, 2000). In sum, the survey 
was reduced to 61 items, and the results project that the survey instrument is capable of operationalizing the predictor variables of interest and testing the relationships among those variables. 


\section{CHAPTER IV}

\section{RESULTS}

\section{Correlation}

Prior to conducting the regressions, a screening of the data was conducted to test for potential differences between different groups or sets of participants. First, two correlations were run to test for differences between groups based on size, one in regard to the survey item asking participants to identify the number of times they believed groupthink occurred within their group, and the other for the item asking participants to rate on a scale from one to nine, how disastrous they believed their group's decision to be. Results produced a statistically significant correlation $(r=.13, p<.05)$ between group size and the number of groupthink occurrences. However, no statistically significant correlation was found $(r=.04, p>.05)$ for group size and the rating of groupthink disaster.

\section{Independent Samples $t$-Test}

Next, two sets of independent samples $t$-tests were run to test for differences between face-to-face and virtual groups, and between student and working adult groups. First, an independent samples $t$-test was calculated to compare the mean scores of participants in face-to-face groups and those in virtual groups based on the number of times groupthink occurred in their group. For face-to-face and virtual groups, the $t$-tests revealed no statistically significant differences $(t(.980)=3.355, p>.05)$. Therefore, face- 
to-face groups did not have higher mean scores for the number of groupthink occurrences $(M=21.01, S D=17.86)$ than did computer mediated groups $(M=17.30, S D=7.94)$. Additionally, another independent samples $t$-test was calculated to compare the mean scores of participants in face-to-face groups and those in virtual groups based on the rating of groupthink disaster in their group. For face-to-face and virtual groups, the $t$-tests revealed no statistically significant differences $(t(-.676)=1.125, p>.05)$. Therefore, face-to-face groups also did not have higher mean scores for the rating of groupthink disaster $(M=3.49, S D=2.57)$ than did computer mediated groups $(M=3.87, S D=2.30)$.

Finally, 12 independent samples $t$-tests were calculated to compare the mean scores of student and working adult participants on the 12 composite variables. For Highly Cohesive, the $t$-tests revealed no statistically significant differences $(t(-1.721)=$ $.232, p>.05)$. Therefore, student groups did not have higher mean scores for cohesiveness $(M=3.35, S D=.88)$ than did adult groups $(M=3.56, S D=.88)$. For Leader Dogmatism, the $t$-tests revealed no statistically significant differences $(t(1.647)=$ $1.477, p>.05)$. Therefore, student groups did not have higher mean scores for leader dogmatism $(M=3.13, S D=.78)$ than did adult groups $(M=2.96, S D=.83)$. For Leader Immediacy, the $t$-tests revealed no statistically significant differences $(t(2.162)=.062, p$ $>$.05). Therefore, student groups did not have higher mean scores for leader immediacy $(M=2.62, S D=.86)$ than did adult groups $(M=2.36, S D=.86)$. For Self-Censorship, the $t$-tests revealed no statistically significant differences $(t(1.422)=.206, p>.05)$. Therefore, student groups did not have higher mean scores for self-censorship $(M=2.95$, $S D=.83)$ than did adult groups $(M=2.79, S D=.82)$. For Free Discussion, the $t$-tests revealed no statistically significant differences $(t(.369)=.007, p>.05)$. Therefore, 
student groups did not have higher mean scores for free discussion $(M=2.51, S D=.87)$ than did adult groups $(M=2.46, S D=.91)$. For Mindguarding, the $t$-tests revealed no statistically significant differences $(t(2.027)=.274, p>.05)$. Therefore, student groups did not have higher mean scores for mindguarding $(M=3.08, S D=.81)$ than did adult groups $(M=2.85, S D=.82)$. For Reservation Encouragement the $t$-tests revealed no statistically significant differences $(t(-.050)=3.843, p>.05)$. Therefore, student groups did not have higher mean scores for encouraging reservations $(M=2.70, S D=.79)$ than did adult groups $(M=12.71, S D=.90)$.

For Anxiety, the $t$-tests revealed no statistically significant differences $(t(1.934)=$ $2.612, p>.05)$. Therefore, student groups did not have higher mean scores for anxiety $(M$ $=3.11, S D=.89)$ than did adult groups $(M=2.86, S D=1.00)$. For Collective Efficacy, the $t$-tests revealed no statistically significant differences $(t(.004)=1.164, p>.05)$. Therefore, student groups did not have higher mean scores for collective efficacy $(M=$ $3.41, S D=.71)$ than did adult groups $(M=3.41, S D=.77)$. For Hidden Profiles, the $t$ tests revealed no statistically significant differences $(t(1.252)=.148, p>.05)$. Therefore, student groups did not have higher mean scores for hidden profiles $(M=2.73, S D=.79)$ than did adult groups $(M=2.59, S D=.84)$. For Trusting Culture, the $t$-tests revealed no statistically significant differences $(t(.035)=1.466, p>.05)$. Therefore, student groups did not have higher mean scores for a trusting culture $(M=3.42, S D=.74)$ than did adult groups $(M=3.41, S D=.85)$. Lastly, for Overly Trusting, the $t$-tests revealed no statistically significant differences $(t(1.638)=1.961, p>.05)$. Therefore, student groups also did not have higher mean scores for having too much trust $(M=2.72, S D=.84)$ than did adult groups $(M=2.52, S D=.98)$. The findings for the independent samples $t$-tests 
comparing students to working adults indicated that no statistically significant differences existed between the groups. Consistent with expectations, the results suggested that the two groups of participants did not differ with respect to scores on any of the 12 composite variables. Thus, these non-significant findings allow for data from both groups of participants to be combined for use in further analysis.

\section{Multiple Linear Regression}

Two different criterion variable models were run through multiple linear regression procedures. Specifically, separate regression models were calculated for the number of times participants believed their group committed groupthink, and for how disastrous participants believed their group's decision to be on a scale from one to ten. The two separate multiple linear regression analyses, which reveal relationships among variables explored in a study, were conducted to test RQ3 and each hypotheses posited in the present study. Multiple linear regression analysis controls for the other predictor variables measured in the study in order to isolate the ability of any single predictor variable to predict a statistically significant amount of variance in the criterion variable. There are several methods that exist for entering variables into a regression model. However, the method chosen for the present study was a backwards entry method. What this means is that initially, all the predictor variables can be entered into the full model regression and then, individual predictor variables are removed from the model using a backward solution if they fail to make statistically significant contributions to the model (Hinkle et al., 2003; Mertler \& Vannatta, 2005; Meyers et al., 2006). When interpreting the statistical output of a multiple regression procedure, it is essential to evaluate certain statistical output. Rejecting the null hypothesis would indicate that multiple $R$ is different 
from zero in the population, thus meaning that a statistically significant relationship exists between the criterion variable and a linear combination of the predictor variables (Hinkle et al., 2003). Meyers at al. noted that "the adjusted $R^{2}$ is a statistical estimate of the 'shrinkage' we would observe if we were to apply the model to another sample" (p. 165), whereas beta weights might not be generalizable to other samples.

\section{Groupthink Occurrence Model}

The first multiple linear regression model was based off the survey item that asked participants to record the number of times they believed their group committed groupthink, accounting for the first criterion variable in the study. The regression model for Groupthink Occurrence investigated whether participants' reported number of times their group committed groupthink could be predicted by a linear combination of Highly Cohesive, Leader Dogmatism, Leader Immediacy, Self-Censorship, Free Discussion, Mindguarding, Reservation Encouragement, Anxiety, Collective Efficacy, Hidden Profiles, Trusting Culture, and Overly Trusting. Therefore, a multiple linear regression analysis utilizing a backwards entry method was conducted to predict Groupthink Occurrence from the composite variables. After all predictor variables were entered into the full regression model, the analysis resulted in nine regression models being calculated as individual composite variables failing to make a significant contribution to the model were removed one predictor at a time.

The first regression model predicted $7.4 \%$ of the variance in Groupthink

Occurrence, $R_{a d j}^{2}=.018, F(12,197)=1.319, p>.05$. The second regression model also indicated that $7.4 \%$ of the variance in Groupthink Occurrence could be predicted by the predictor variables, $R_{a d j}^{2}=.023, F(11,198)=1.445, p>.05$. Model 3 also predicted 
$7.4 \%$ of the variance in Groupthink Occurrence, $R_{a d j}^{2}=.027, F(10,199)=1.585, p>.05$. Model 4 indicated that $7.3 \%$ of the variance in Groupthink Occurrence could be predicted by the predictor variables, $R_{a d j}^{2}=.032, F(9,200)=1.757, p>.05$. The fifth model predicted $7.2 \%$ of the variance in Groupthink Occurrence, $R_{a d j}^{2}=.035, F(8,201)$ $=1.941, p>.05$. The sixth model indicated that $7.0 \%$ of the variance in Groupthink Occurrence could be predicted by the predictor variables, $R_{a d j}^{2}=.038, F(7,202)=2.176$, $p<.05$. Model 7 predicted $6.9 \%$ of the variance in Groupthink Occurrence, $R_{\text {adj }}^{2}=.042$, $F(6,203)=2.511, p<.05$. Model 8 indicated that $6.7 \%$ of the variance in Groupthink Occurrence could be predicted by the predictor variables, $R_{a d j}^{2}=.044, F(5,204)=2.906$, $p<.05$. Lastly, results of the final multiple linear regression analysis (Model 9) indicated that $6.1 \%$ of the variance in Groupthink Occurrence could be predicted by the predictor variables, $R_{a d j}^{2}=.042, F(4,205)=3.300, p<.05$. Thus, the significant results of the regression procedure indicated that the linear combination of four composite variables, Highly Cohesive, Leader Dogmatism, Collective Efficacy, and Trusting Culture were able to account for a statistically significant amount of variance in the criterion variable. A further summary of each regression model for Groupthink Occurrence can be found in Table 10. 
Table 10

Groupthink Occurrence Regression Model Table

\begin{tabular}{cccccccccc}
\hline Models & $R^{2}$ & $R_{a d j}^{2}$ & $\Delta R^{2}$ & $\Delta F$ & $d f 1$ & $d f 2$ & $F$ & $P$ & Sig. $\Delta F$ \\
\hline Model 1 & .074 & .018 & .018 & 1.319 & 12 & 197 & 1.319 & .210 & .210 \\
Model 2 & .074 & .023 & .023 & .013 & 11 & 198 & 1.445 & .155 & .909 \\
Model 3 & .074 & .027 & .027 & .116 & 10 & 199 & 1.585 & .113 & .734 \\
Model 4 & .073 & .032 & .032 & .111 & 9 & 200 & 1.757 & .078 & .739 \\
Model 5 & .072 & .035 & .035 & .337 & 8 & 201 & 1.941 & .056 & .562 \\
Model 6 & .070 & .038 & .038 & .343 & 7 & 202 & 2.176 & $.038^{*}$ & .559 \\
Model 7 & .069 & .042 & .042 & .225 & 6 & 203 & 2.511 & $.023 *$ & .636 \\
Model 8 & .067 & .044 & .044 & .565 & 5 & 204 & 2.906 & $.015^{*}$ & .453 \\
Model 9 & .061 & .042 & .042 & 1.311 & 4 & 205 & 3.300 & $.012 *$ & .254 \\
\hline Note. An * indicates a significant regression model at $p<.05 .(n=209)$ &
\end{tabular}

In the first backwards step, Reservation Encouragement, $\beta=.011, t=.115, p>$ .05 , dropped out after failing to make a significant contribution to the model. Next, Anxiety, $\beta=-.029, t=-.340, p>.05$, dropped out in the second backwards step, followed by Leader Immediacy, $\beta=-.032, t=-.333, p>.05$, in the third backwards step. In the fourth backwards step, Hidden Profiles, $\beta=-.057, t=-.580, p>.05$, dropped out after failing to make a significant contribution to the model, followed by Self-Censorship, $\beta=$ $.053, t=-.585, p>.05$, in the fifth backwards step. Next, Mindguarding, $\beta=.046, t=$ $.475, p>.05$, dropped out in the sixth backwards step, followed by Overly Trusting, $\beta=-$ $.056, t=-.752, p>.05$, in the seventh backwards step. Finally, in the eighth backwards step, Free Discussion, $\beta=.096, t=1.145, p>.05$, dropped out after failing to make a significant contribution to the model.

Analysis of regression coefficients indicated that Highly Cohesive, $\beta=.216, t=$ 2.361, $p<.05$, and Trusting Culture, $\beta=-.338, t=-2.972, p<.05$, were statistically significant individual predictors of Groupthink Occurrence, meaning that they uniquely 
explained a significant percentage of the variance in Groupthink Occurrence. Squared part correlations revealed that Highly Cohesive uniquely predicted $2.56 \%$ of the variance and Trusting Culture uniquely predicted $4.04 \%$ of the variance. While they were still a part of the final model and therefore are important, neither Leader Dogmatism, $\beta=-.141$, $t=-1.961, p>.05$, or Collective Efficacy, $\beta=.191, t=1.898, p>.05$, were significant individual predictors of Groupthink Occurrence. None of the variables produced TOL or VIF statistics indicating collinearity. Beta weights for the final Groupthink Occurrence regression model can be found in Table 11.

Table 11

Beta Weights for Final Groupthink Occurrence Model

\begin{tabular}{|c|c|c|c|}
\hline Predictor Variables & $B$ & $S E B$ & $\beta$ \\
\hline Highly Cohesive & 4.175 & 1.768 & $.216^{*}$ \\
\hline Leader Dogmatism & -2.986 & 1.523 & -.141 \\
\hline Collective Efficacy & 4.423 & 2.331 & 191 \\
\hline Trusting Culture & -7.291 & 2.454 & $-.338^{*}$ \\
\hline & \multicolumn{3}{|c|}{.061} \\
\hline & \multicolumn{3}{|c|}{.042} \\
\hline & \\
\hline
\end{tabular}

Note. An $*$ indicates a unique significant predictor variable at $p<.05 .(n=209)$

The final regression model provided support for $\mathrm{H} 1$ and $\mathrm{H} 6$, and partial support for $\mathrm{H} 2$ and $\mathrm{H} 8$. Thus, as hypothesized, group cohesiveness, promotional leadership, collective efficacy, and trust were found to be predictors of the number of occurrences of groupthink. In addition, the linear composite of these four predictor variables was found to predict Groupthink Occurrence. However, the findings failed to support H3, H4, H5, 
and H7. In other words, contrary to expectations, conformity, concurrence seeking, anxiety, and hidden profiles were not found to be predictors of the number of groupthink occurrences.

\section{Groupthink Disaster Model}

The second multiple linear regression model was based off of the survey item which asked participants to rate on a scale from one to nine, how disastrous they believed their group's decision to be, accounting for the second criterion variable of the study. One would expect a rating of one to mean very little or no groupthink, a rating of two to four to represent very little groupthink, five to be neutral, and a rating of six to nine to mean a disastrous decision likely characterized by groupthink. The regression model for Groupthink Disaster investigated whether participants' reported indication of how disastrous their group's decision was could be predicted by a linear combination of Highly Cohesive, Leader Dogmatism, Leader Immediacy, Self-Censorship, Free Discussion, Mindguarding, Reservation Encouragement, Anxiety, Collective Efficacy, Hidden Profiles, Trusting Culture, and Overly Trusting. Therefore, a multiple linear regression analysis utilizing a backwards entry method was conducted to predict Groupthink Disaster from the composite variables. After all predictor variables were entered into the full regression model, the analysis resulted in nine regression models being created as individual composite variables failing to make a significant contribution to the model were removed one predictor at a time.

The first regression model predicted $17.3 \%$ of the variance in Groupthink Disaster, $R_{a d j}^{2}=.122, F(12,195)=3.392, p<.05$. The second regression model also indicated that $17.3 \%$ of the variance in Groupthink Disaster could be predicted by the 
predictor variables, $R_{a d j}^{2}=.126, F(11,196)=3.719, p<.05$. Model 3 also predicted $17.3 \%$ of the variance in Groupthink Disaster, $R_{a d j}^{2}=.131, F(10,197)=4.108, p<.05$. Model 4 indicated that $17.2 \%$ of the variance in Groupthink Disaster could be predicted by the composite variables, $R_{a d j}^{2}=.134, F(9,198)=4.567, p<.05$. The fifth regression model predicted $17.0 \%$ of the variance in Groupthink Disaster, $R_{a d j}^{2}=.137, F(8,199)=$ $5.106, p<.05$. The sixth regression model indicated that $16.8 \%$ of the variance in Groupthink Disaster could be predicted by the predictor variables, $R_{a d j}^{2}=.138, F(7,200)$ $=5.751, p<.05$. Model 7 predicted $16.5 \%$ of the variance in Groupthink Disaster, $R_{a d j}^{2}=$ $.140, F(6,201)=6.605, p<.05$. Model 8 indicated that $15.9 \%$ of the variance in Groupthink Disaster could be predicted by the composite variables, $R_{a d j}^{2}=.138, F(5$, $202)=7.635, p<.05$. Lastly, results of the final multiple linear regression analysis (Model 9) indicated that $15.3 \%$ of the variance in Groupthink Disaster could be predicted by the predictor variables, $R_{a d j}^{2}=.136, F(4,203)=9.133, p<.05$. Thus, the significant results of the regression procedure indicated that the linear combination of four composite variables, Free Discussion, Anxiety, Collective Efficacy, and Overly Trusting were able to account for a statistically significant amount of variance in the criterion variable. Additionally, this process produced interesting results as every single backwards step model in Groupthink Disaster was found to be significant. A further summary of each regression model for Groupthink Disaster can be found in Table 12. 
Table 12

Groupthink Disaster Regression Model Table

\begin{tabular}{cccccccccc}
\hline Models & $R^{2}$ & $R_{a d j}^{2}$ & $\Delta R^{2}$ & $\Delta F$ & $d f 1$ & $d f 2$ & $F$ & $p$ & Sig. $\Delta F$ \\
\hline Model 1 & .173 & .122 & .173 & 3.392 & 12 & 195 & 3.392 & $.000^{*}$ & .000 \\
Model 2 & .173 & .126 & .000 & .005 & 11 & 196 & 3.719 & $.000^{*}$ & .941 \\
Model 3 & .173 & .131 & .000 & .027 & 10 & 197 & 4.108 & $.000^{*}$ & .869 \\
Model 4 & .172 & .134 & -.001 & .158 & 9 & 198 & 4.567 & $.000^{*}$ & .692 \\
Model 5 & .170 & .137 & -.002 & .380 & 8 & 199 & 5.106 & $.000^{*}$ & .538 \\
Model 6 & .168 & .138 & -.003 & .656 & 7 & 200 & 5.751 & $.000^{*}$ & .419 \\
Model 7 & .165 & .140 & -.003 & .692 & 6 & 201 & 6.605 & $.000^{*}$ & .407 \\
Model 8 & .159 & .138 & -.006 & 1.381 & 5 & 202 & 7.635 & $.000^{*}$ & .241 \\
Model 9 & .153 & .136 & -.006 & 1.545 & 4 & 203 & 9.133 & $.000^{*}$ & .215 \\
\hline
\end{tabular}

Note. An * indicates a significant regression model at $p<.05 .(n=207)$

In the first backwards step, Self-Censorship, $\beta=.007, t=.074, p>.05$, dropped out after failing to make a significant contribution to the model. Next, Leader Immediacy, $\beta=-.015, t=-.165, p>.05$, dropped out in the second backwards step, followed by Trusting Culture, $\beta=-.050, t=-.397, p>.05$, in the third backwards step. In the fourth backwards step, Reservation Encouragement, $\beta=.052, t=.616, p>.05$, dropped out after failing to make a significant contribution to the model, followed by Mindguarding, $\beta=.079, t=.810, p>.05$, in the fifth backwards step. Next, Leader Dogmatism $\beta=-$ $.061, t=-.832, p>.05$, dropped out in the sixth backwards step, followed by Hidden Profiles, $\beta=.102, t=1.175, p>.05$, in the seventh backwards step. Finally, in the eighth backwards step, Highly Cohesive, $\beta=.107, t=1.243, p>.05$, dropped out after failing to make a significant contribution to the model.

Analysis of regression coefficients indicated that Free Discussion, $\beta=.168, t=$ 2.336, $p<.05$, Anxiety, $\beta=.162, t=2.342, p<.05$, Collective Efficacy, $\beta=-.147, t=-$ 
2.016, $p<.05$, and Overly Trusting, $\beta=.167, t=2.434, p<.05$, were significant individual predictors of Groupthink Disaster, meaning that they uniquely explained a significant percentage of the variance in Groupthink Disaster. Squared part correlations revealed that Free Discussion uniquely predicted $2.28 \%$ of the variance, Anxiety uniquely predicted $2.28 \%$ of the variance, Collective Efficacy uniquely predicted $1.69 \%$ of the variance, and Overly Trusting uniquely predicted $2.46 \%$ of the variance. None of the variables produced TOL or VIF statistics indicating collinearity. Beta weights for the final Groupthink Disaster regression model can be found in Table 13.

Table 13

Beta Weights for Final Groupthink Disaster Model

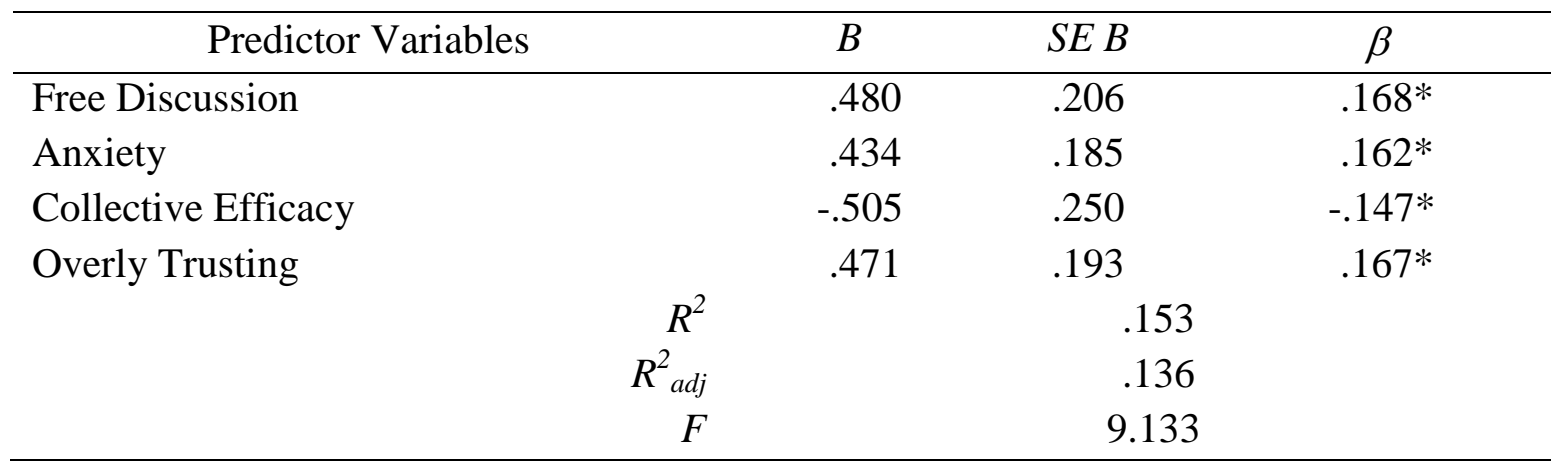

Note. An * indicates a unique significant predictor variable at $p<.05 .(n=207)$

The final regression model provided support for $\mathrm{H} 5$ and $\mathrm{H} 6$, and partial support for $\mathrm{H} 3$ and $\mathrm{H} 8$. Thus, as hypothesized, conformity, anxiety, collective efficacy, and trust were found to be significant predictors of the disastrousness of groupthink. In addition, as hypothesized, the linear composite of these four predictor variables was found to predict groupthink disastrousness. However, the findings failed to support $\mathrm{H} 1, \mathrm{H} 2, \mathrm{H} 4$, and $\mathrm{H} 7$. 
In other words, contrary to expectations, group cohesiveness, promotional leadership, concurrence seeking, and hidden profiles were not found to be predictors of the disastrousness of groupthink.

\section{Summary}

In summary, a correlation demonstrated a significant relationship between group size and the number of groupthink occurrences reported, but failed to find a significant relationship between group size and the rating of groupthink disaster. Further, the first set of independent samples $t$-tests found no significant differences between whether groups were face-to-face or virtual in regard to both the number of times groupthink was reported to occur, and the level of disastrousness of groupthink reported. A second set of independent samples $t$-tests confirmed that student and working adult groups did not significantly vary in regard to any of the 12 composite variables, which allowed for further comparison of the data. Lastly, two regression analyses were conducted using all 12 composite predictor variables, with one analyzing the number of groupthink instances reported by the participant as the criterion variable, and the other analyzing the disastrousness of the decision reported by the participant as the criterion variable. For the Groupthink Occurrence model, Highly Cohesive, Leader Dogmatism, Collective Efficacy, and Trusting Culture were predictors of the number of groupthink occurrences, while the Groupthink Disaster model showed Conformity, Anxiety, Collective Efficacy, and Overly Trusting to be significant predictors of the disastrousness of groupthink. While examining the results of the regression analyses together, $\mathrm{H} 4$ and $\mathrm{H} 7$ were not supported in either model. $\mathrm{H} 1, \mathrm{H} 2, \mathrm{H} 3$, and $\mathrm{H} 5$ were all supported in one of the two regressions, resulting in partial support for the predictions in regard to groupthink. Lastly, 
$\mathrm{H} 6$ and $\mathrm{H} 8$ received support in both regression models, resulting in an overall support for the hypotheses and an answer for RQ3. Overall, these results help to paint a more parsimonious picture about what can predict groupthink. There are many different variables suggested to lead to the phenomenon; however, this study measured the predictors deemed to be the most important, and the results narrowed these variables down to six variables that can tap into groupthink either in the form of Groupthink Occurrence, Groupthink Disaster, or both. 


\section{CHAPTER V \\ DISCUSSION}

The primary goal of this study was to determine if groupthink could be assessed by a linear combination of predictor variables, thus creating a survey instrument to measure a group's tendency or likelihood toward committing the phenomenon. Specifically, student participants and working adults answered a series of questions about their group's communication process. These questions incorporated concepts such as highly cohesive groups, promotional leadership, conformity, concurrence seeking anxiety, collective efficacy, hidden profiles, and trust. The final data analysis sought to determine if the predictor variables were able to account for a significant amount of variance in the number of groupthink occurrences and ratings of groupthink disaster. This chapter will summarize the findings of the study and unpack the implications for not only researchers on the subject, but for groups from all walks of life or areas of society to better make sense of their experiences and protect against faulty decision-making processes, such as groupthink.

\section{Summary of Findings}

The overall purpose of the present study was to determine the factors that are most prevalent when considering group experiences that are characterized by pronounced negative decisions and potentially, by groupthink. More simply put, the research sought to determine what makes a group more likely to commit groupthink. The EFA procedures 
and acceptable reliability estimates indicated that the eight original scales, of which four were found to be multidimensional and four were found to be unidimensional, were able to be factored into 12 composite variables. Thus, the EFA procedures established content validity for the survey instrument (DeVellis, 2003; de Vaus, 2001; Frey et al., 2000). Therefore, groupthink can be measured by a linear combination of the predictor variables in the form of various scales and subscales. The single-factor Highly Cohesive scale consisted of three items, while the two-factor Promotional Leadership scale consisted of five items related to Leader Dogmatism and three items related to Leader Immediacy. The two-factor Conformity scale was made up of five items relating to Self-Censorship and two items relating to Free Discussion, while the two-factor Concurrence Seeking scale consisted of six items related to Mindguarding and two items related to Reservation Encouragement. The single-factor Anxiety, Collective Efficacy, and Hidden Profiles scales consisted of five items, seven items, and three items respectfully. Lastly, the twofactor Trust scale was made up of six items relating to Trusting Culture and two items relating to Overly Trusting. Overall, the development of this groupthink survey represents an important step forward in the study of the phenomenon not only in relation to communication, but in gaining an inclusive conceptualization and operationalization of the concept that can be better accepted and utilized by all.

\section{Comparison of Groups}

When $t$-tests were run independently for each factor in relation to whether participants were students or working adults, the analysis produced consistently nonsignificant results for all 12 composite variables. This was consistent with expectations, suggesting that the two groups of participants did not differ with respect to scores on any 
of the 12 composite variables. When $t$-tests were run to test for differences between faceto-face and virtual groups in regard to participant's reported number of Groupthink Occurrence, and their rating of Groupthink Disaster, the analyses again produced consistently non-significant results.

\section{Regression Models}

For the first regression model, a combination of four composite variables, Highly Cohesive, Leader Dogmatism, Collective Efficacy, and Trusting Culture, accounted for a statistically significant portion of the variance $(6.1 \%)$ in the criterion variable of

Groupthink Occurrence. For the second regression model, a different combination of four composite variables, Free Discussion, Anxiety, Collective Efficacy, and Overly Trusting, accounted for a statistically significant portion of the variance $(15.3 \%)$ in the criterion variable of Groupthink Disaster. When examining predictors individually, collective efficacy and trust emerged as a statistically significant predictor of both Groupthink Disaster and Groupthink Occurrence, demonstrating the conceptual link between the concepts and groupthink. Additionally, highly cohesive groups, promotional leadership, conformity, and anxiety all received partial support as predictors of groupthink.

\section{Hypotheses}

The first hypothesis stated that as group cohesion increases, the propensity to commit groupthink also increases. Cohesion was found to be a statistically significant predictor and uniquely accounted for a statistically significant amount of the variance under the Groupthink Occurrence model, but was not the case under the Groupthink Disaster model. Thus, H1 was partially supported. This is in line with Paskevich et al.'s (2001) finding that cohesion is related to groupthink and a pressure to conform, and with 
Glaser's (1993) statement that groupthink can develop as a group becomes more cohesive and less critical of its own decisions.

The second hypothesis stated that groups whose leader communicates in a way that promotes their preferred choice are more likely to commit groupthink. Promotional leadership was found to be a predictor under the Groupthink Occurrence model, but was not the case under the Groupthink Disaster model. Thus, $\mathrm{H} 2$ was partially supported. Therefore, this study was able to reach the same conclusion as Esser (1998) that promotional leadership relates to the presence of groupthink symptoms, symptoms of poor decision processes, and poor decision quality.

The third hypothesis deals with the relationship between conformity and groupthink. Findings indicate that there is a relationship between conformity and groupthink because conformity was a statistically significant predictor and uniquely accounted for a statistically significant amount of the variance in the Groupthink Disaster model. However, this was not the case under the Groupthink Occurrence model. Thus, H3 was partially supported. Therefore, the findings are able to reach the same conclusion as Courtright (1978) that the presence or absence of conformity is a significant discriminator between groupthink and non-groupthink groups.

The fourth hypothesis stated that groups whose members communicate higher levels of consensus are more prone to commit groupthink. Concurrence seeking was not found to be a predictor under either the Groupthink Disaster or the Groupthink Occurrence models. Thus, $\mathrm{H} 4$ was not supported. This does not coincide with Longley and Pruitt's (1980) conclusion that groupthink is appropriate only when concurrence seeking within a group emerges prematurely, thus decreasing thinking and discussion, 
and increasing the possibility of a poor decision outcome. One reason for this nonsignificant finding could be due to the low variance accounted for by the Concurrence Seeking scale (50.959\%), which suggests that there may be another factor involved with concurrence seeking, or that a dimension may be missing that the scale could not explain. Additionally, another part of the problem in regard to the instrument itself may have been the way the questions were worded. For example, it may be that concurrence seeking works in a way that is not always obvious to a group member; perhaps sometimes on a subconscious level, making it hard to recall or report later. Or, the failure to support the concurrence seeking variable could be a social desirability bias, where participants are hesitant to admit to group pressures to agree with the majority opinion. This could be especially true if participants were the ones applying this pressure or contributing to a negative group communication process. A final reason for not supporting this hypothesis could be that it is simply as not as predictive of groupthink as the other predictive variables, which is still valuable information that contributes to our ever-growing understanding of the phenomenon. This thought, however, is not in line with Janis and Mann (1979), who identified concurrence seeking as the entire second stage of their original model.

The fifth hypothesis deals with the relationship between anxiety and groupthink. Findings indicate that there is a relationship between anxiety and groupthink because anxiety was a statistically significant predictor and uniquely accounted for a statistically significant amount of the variance in the Groupthink Disaster model. However, this was not the case under the Groupthink Occurrence model. Thus, H5 was partially supported. This finding is in line with Janis and Mann's (1977) decision conflict theory, which states 
that decision makers, when under stressful conditions, resort to "hypervigilant" strategies for information processing, which become representative of frantic searches for a solution and a failure to consider all alternatives. This also matches up with Chapman (2006), who said that anxiety can divert attention away from the problem at hand as reducing anxiety operates as an implicit motivator where decision makers become more concerned with reducing their feelings of anxiety than with finding the best solution.

The sixth hypothesis stated that groups whose members communicate noticeably higher levels of perceived collective efficacy will be more likely to commit groupthink. Collective efficacy was found to be a statistically significant predictor under both the Groupthink Occurrence and Groupthink Disaster models, and uniquely accounted for a statistically significant amount of the variance under the Groupthink Disaster model. Thus, H6 was supported, and collective efficacy emerged as one of the strongest predictor variables of groupthink, providing half of the answer for RQ3. Therefore, this matches Whyte's (1998) claim that the symptoms of groupthink can result from overconfidence, or an excessive level of collective efficacy, and also matches up with Whyte, Saks, and Hook's (1997) conclusion that there is a tendency to escalate commitment to a losing course of action by increasing strong efficacy beliefs.

The seventh hypothesis deals with the relationship between hidden profiles and groupthink. Findings indicate that there is not a relationship between hidden profiles and groupthink because hidden profiles were not a predictor of groupthink in both the Groupthink Occurrence and Groupthink Disaster models. Thus, H7 was not supported. Therefore, this study was unable to reach the same conclusion as Henningsen et al. (2006) that the hidden profile problem is very similar to the issue of compliance pressure 
in groupthink, and that groups with more information are more confident in their choice, creating an illusion of invulnerability, which can make them more likely to fall victim to groupthink or suffer from a disastrous choice. One reason for this non-significant finding could be that it is hard for participants to report hidden profiles, which work on almost a subliminal level, where group members may not be aware of their existence. This is the whole idea of a hidden profile in the first place; it is "hidden" and, therefore, is a construct with ramifications that are a little more complex, but also harder to measure. It may be the case that the best way to get at this concept is through a more experimental type of design, with controls to determine the effect of hidden profiles on groupthink with more certainty. Another potential reason for failing to support this hypothesis could be because, similar to the result of concurrence seeking, there was a low variance accounted for by the Hidden Profiles scale (54.535\%), suggesting that there may be another dimension involved with this factor that the scale could not explain.

The eighth and final hypothesis stated that groups whose members communicate higher levels of trust will be more likely to commit groupthink. Trust was found to be a statistically significant predictor and uniquely accounted for a statistically significant amount of the variance under both the Groupthink Occurrence and Groupthink Disaster models. Thus, the final hypothesis was supported, and trust emerged as one of the strongest predictor variables of groupthink, providing the other half of the answer for research question three. This also supports Erdem's (2003) assertion that too much trust can be risky or could result in groupthink as group members begin to self-censor as to not deviate from the perceived consensus. Additionally, this result is in line with Manz and Neck's (1995) conclusion that when teams do not discuss or sufficiently analyze 
alternative courses of action due to trust, they increase the possibility of wrong or ineffective decision-making characterized by groupthink.

\section{Implications}

\section{Theoretical Implications}

The major contribution of the present study is recognizing that collective efficacy and trust are statistically significant predictors of groupthink, and that high cohesiveness, conformity, and anxiety are also predictors of the phenomenon, as individuals should work to de-emphasize these concepts within their groups in order to reach a more desirable outcome or decision, and to reduce the chances of groupthink. Furthermore, promotional leadership was found to be a predictor for the Groupthink Occurrence regression model only. Previous research on groupthink showed that there are many different variables suggested to lead to the phenomenon; however, this study measured the predictors deemed to be the most important, and the results narrowed these variables down to six. Overall, these results allow the construction of a more simple way to look at groupthink and what can predict it. Additionally, the present study helps to solve the catch-22 dilemma involved with groupthink and it has operationalized the concept into a more measurable format. The study has successfully begun the process of creating an appropriate instrument for measuring groupthink and tapping into its variables. Even though groupthink does not always occur given the same set of predictors and decisionmaking defects, understanding what can lead to it is of the upmost importance, and this study has generated a more precise way of analyzing the groupthink model thanks to the predictors and composite variable scales identified through the regression models and EFA. 
Another major theoretical implication of the present study relates to Janis' (1972, 1982) original model and conceptualization of groupthink. Although his original model has been often criticized and seldom empirically supported, four of the predictor variables in the current study based upon or identified by Janis were partially supported. Thus, despite all of the critiques of Janis' model and the conditions he described as necessary for groupthink to occur (e.g., Moorhead \& Montanari, 1986; Whyte, 1998), such as cohesiveness, anxiety, promotional leadership, and conformity, this study has provided support for them, statistically speaking, and suggests that his original model and predictor variables likely are not far off from what actually takes place. Although these original concepts and variables associated with groupthink and predicted by Janis have garnered large amounts of research and critique (e.g., Baron, 2005; Fuller \& Aldag, 1998; Henningsen et al., 2006; Park, 2000), they continue to appear throughout the review of literature and are accepted in the present study. Additionally, although the original concepts hypothesized to be important by Janis need to continue to be considered, such as cohesiveness, promotional leadership, conformity, and anxiety, so should additions to the model, such as collective efficacy (Whyte, 1998), and trust (Manz and Neck, 1995), resulting in a combination of Janis' original design and proposed alternatives.

\section{Practical Implications}

The predictor variables identified as contributing to groupthink through this study, and therefore that need to be discussed from a practical standpoint as groups and their members should work to avoid them during the decision-making process, or even before such processes begin, were trust, cohesiveness, anxiety, collective efficacy, promotional leadership, and conformity. Trust and cohesiveness made predicting Groupthink 
Occurrence likely, while promotional leadership and collective efficacy added to the picture surrounding the model. For the Groupthink Disaster model, all four predictor variables, trust, anxiety, collective efficacy and conformity, were statistically significant predictors. Therefore, it is important to view these variables as solutions and ways to guard against groupthink, and it is important to make sure these are not occurring within decision-making groups.

First, although trust is a required condition for teamwork and effective communication, too much trust can be risky or could result in groupthink, as how Erdem (2003) put it, when group members begin to self-censor as to not deviate from the perceived consensus. Groups should work not to apply social pressures to those who argue or disagree with the group's shared beliefs, not to try to rationalize decisions within their values and norms, and not to pursue agreement in all situations. When teams do not sufficiently discuss or analyze other courses of action due to too much trust, they increase the possibility of wrong or ineffective decision-making (Manz \& Neck, 1995). This understanding of too much trust as a negative concept in group decision-making appears to be one of the most notable findings and contributions of the present study in regard to groupthink.

It is not an easy task to find the appropriate level of trust in groups, and it requires recognizing the positive and negative aspects of both trust and distrust concurrently (Erdem, 2003). Group members need to communicate and work together to express their views openly, and to establish strong lines of information and resource sharing. They should also search for diversity in opinions and remain skeptical about courses of action until all alternatives are inquired about. Each of these recommendations, according to 
Erdem, function as tools of distrust, but in a positive manner, and, hopefully, help lead to a positive outcome. Overall, group members should communicate in a way that is both critical and constructive in order to avoid the risk of too much trust negatively impacting group performance.

When it comes to cohesiveness in regard to communication and groupthink, it is important for groups to remain critical and ask questions during deliberation. Members of highly cohesive groups are less likely to generate truly innovative ideas or approaches to a problem because individual effort and attention can become consumed with staying within the norms and boundaries set by the group (Hackman, 1992). High cohesiveness is seen as a negative occurrence in instances of groupthink as it causes members to not want to "rock the boat," and it certainly does not always help to lead groups to a better performance.

While certain amounts of group trust and cohesiveness have clear benefits until they reach a certain tipping point and can begin to predict groupthink, the next predictor variable found to be statistically significant in one of the regression models in this study has no clear tipping point. Janis (1982) linked two of the predictor variables found to be statistically significant in different regression models in the present study when he noted that stress-reducing tendencies related to anxiety are more likely in groups that are highly cohesive. Additionally, Turner et al. (1992) found that when levels of stress and anxiety surrounding a group are high, group members exhibit more rationalization behaviors when trying to process information. This is obviously not an effective way to try to circumvent groupthink when the predictor variables of trust and highly cohesive groups highlight the need for critical thinking, argumentativeness, and open discussions. 
In addition to anxiety having a damaging effect on decision makers by affecting the ways in which they process information, which is poorer under negative affect, anxiety may also increase the tendency toward excessive risk taking in some groups, and can divert attention away from the problem at hand. According to Chapman (2006), anxiety can function as an implicit motivator where decision makers become more concerned with reducing the feelings of anxiety, than with finding the best solution to the current problem. This is problematic because when a group is more concerned with reducing their feelings of anxiety as opposed to focusing on the problem at hand and making the best decision, groupthink become a very real and looming possibility. Additionally, anxiety tarnishes one's ability to communicate about decisions by decreasing or splitting their resources and priorities. Chapman said that stress creates an imbalance between an individual's ability to cope with anxiety and environmental demands, which interferes with optimal decision processes, and according to Leon and Revelle (1985), attempting to reduce uncertainly can interfere with and limit appropriate cognitive functioning, increasing the likelihood for errors in cognitive tasks. Lastly, the final consequences of being caught up with managing anxiety is that it often elicits a defensive response in group members that can result in them deceiving themselves, and losing their grip on what is real (Carlson \& Hatfield, 1992).

Next, groupthink and its symptoms have been linked to overconfidence and an excessive level of collective efficacy (Whyte, 1998), which is when groups become complacent with their communication and process of decision-making. It is the joint belief a group has about its ability to successfully perform a task or solve a problem. Risk-seeking in groups increases when perceptions of collective efficacy exceed actual 
capacity or, in simpler terms, when a strong "can do" attitude causes groups to take excessive risks to avoid the possible loss of a desired outcome. The hazards of collective efficacy extend to groups or group members holding onto failing courses of action, almost being stubborn or "thick headed." This type of attitude can work to make the situation or outcome even worse than it originally would have been (Staw \& Ross, 1987). Research has shown that efficacy affects the escalation tendency and saying power of ineffective communication process, procedures, or unsuccessful courses of action (Whyte, 1998; Whyte et al., 1997). Overall, the present study shows that groupthink, both in regard to Groupthink Occurrence and Groupthink Disaster, is more likely to arise when a group communicates higher levels of commitment to an unproductive decision, or plan of action, before fully exploring other potential choices or allowing opposite opinions to be raised.

In regard to promotional leadership, groups with leaders who communicate in a way that endorses their own preference have been found to discuss fewer facts and bring up fewer solutions than groups with a leader who encourages the expression of different viewpoints (Flowers, 1977). Additionally, groups with leaders who have a high need for power are more likely to communicate in a way that expresses their own viewpoint in a prevailing manner (Foder \& Smith, 1982), and promotional leaders are more likely to discourage dissenting views, adopt an illusion or morality, allow for a lesser discussion of the facts and alternatives, and express fewer moral concerns then those utilizing less promotional leadership behaviors (Moorhead \& Montanari, 1986). Therefore, the present study suggests that group leaders should work toward being more participative in an 
effort to allow for better information sharing and to not sway hidden profile groups to show stronger support for a poorer decision.

When it comes to the final predictor identified as important in the current study, conformity, defects during group decision-making, and a failure to consider other plans of action can result from group members having the illusionary perception that they have a unanimous decision, making groups more likely to conclude too early. This is often revealed through self-censorship. Additionally, conformity can cause groups members to pressure others in the group to "hold their tongue" (mindguarding), resulting in other group members potentially remaining silent even if they disagree with what they perceive to be the majority opinion. An overarching theme or conclusion concerning the effects of conformity is that serious problems can begin to emerge within group communication when members begin to doubt or question their own viewpoints. This process of conformity, mindguarding, and self-censorship can often lead to a false consensus. Therefore, it is important for group members to exhibit signs and behaviors of argumentativeness, which is arguing only ideas presented instead of attacking other group members themselves, because it can contribute to a more positive communication climate and a willingness to take a constructive stand.

A final practical implication of the current study is an understanding of the predictors of groupthink as skills to learn, practice, and improve upon in an effort to avoid groupthink or problematic decision-making processes. Each of the variables supported in this study can be viewed as having tipping points wherein they become dangerous to the group and its' communication process. Therefore, by instructing groups and individuals about the danger of these potential tipping points and ways to guard 
against groupthink, the process of treating groupthink as a consequence of poor communication and group deliberation can begin; as opposed to the former way of examining groupthink based on a certain kind of outcome or decision. Because groupthink does not always occur under the same circumstances or set of predictors, but sometimes appears to occur by random chance (e.g., Flippen, 1999; Hirokawa et al., 1988; Kramer \& Dougherty, 2013), this can be dangerous as it can set a pattern of bad behavior for a group where they come to believe they can get away with their poor group processes. When a group believes they can get away with poor decision-making, or even groupthink, this makes it even more difficult to coach them on the importance of groupthink and how to avoid it. Therefore, we may need to begin examining and approaching conditions that predict groupthink as more important to avoid, than groupthink itself.

\section{Limitations}

Although this study provides valuable insight into what helps groups combat against the occurrence of groupthink, it is still hampered by a number of limitations. In fact, although studies may find statistically significant results that affirm their hypotheses, no study is without limitations. One limitation of this study is the way the surveys of student participants were collected. Due to the fact that students mainly accessed the survey through the research pool webpage, this severely limits the number of students who were aware of the survey and able to take it, and also limits the likeliness or reasons for students not involved with a communication course to take it. Although this method is effective overall, and was supplemented by accessing working adult 
participants both within and outside of the university, it does inhibit the chances of attaining a more diverse sample of student participants.

Another limitation of this study relates to the composite variables of Free Discussion, Reservation Encouragement, and Overly Trusting. These variables, or factors, only consisted of two loadings and did not account for as much of the total variance as the other factors did. In fact, they accounted for the three lowest variance totals of all 12 composite variables. If this study were to be duplicated with revised survey questions in the spirit of increasing the variances within these subscales, we would potentially see these variables as being more important or significant than they were in this study.

Next, most of the participants surveyed were from the same community. Results from different communities, or different regions throughout the country, may vary for a number of cultural or other reasons related to participant's experiences or frames of reference. Overall, this research was conducted with a fairly homogenous sample set. These limitations limit the generalizability of the findings. Additionally, some participants may have been primed as to the nature of the survey because of the general group demographic questions that were asked at the beginning of the survey, and if they read the informed consent page closely enough. This also could have inflated the scores of the questions as there may have been a social desirability bias in the survey. Another problem with the current study is the same difficulty every study faces in regard to groupthink, which is the challenge of utilizing the kind of cohesive group Janis' (1982) original model uses. According to Moorhead and Montanari (1986), since cohesiveness is the primary antecedent condition of groupthink, it must develop over time and be present 
in some degree before the decision situation in which groupthink might occur for it to be truly "antecedent." The problem with cohesiveness faced in the current study is similar to the problem researchers encounter when trying to conduct experimental studies on groupthink; although it has been suggested that an instrument allowing participants to reflect on their group experiences that likely involved high levels of cohesion has the potential to be more successful in getting at the concept of groupthink.

Lastly, a study's limitations are often revealed in how the researcher would redesign the study if they were to begin again with the knowledge of hindsight. First, even though the new survey instrument developed for the present study fared well in exploratory factor analyses and demonstrated acceptable to very good scale reliabilities, the instrument could certainly be improved in several areas, most importantly with the subscales consisting of only two items. Further modification and refinement of these subscales would certainly be a worthwhile endeavor. Second, the present study did not allow for a comparison of face-to-face and virtual groups. In other words, how do groups who meet face-to-face differ or compare to more dispersed groups, or even groups who communicate only through virtual channels? Perhaps modifying the survey instrument and setting up the study with a more focused effort on gaining participants from virtual groups would help to answer this type of question. All in all, this research provides a new glimpse at the way groupthink can be affected by a linear combination of eight predictor variables: highly cohesive groups, promotional leadership, conformity, concurrence seeking anxiety, collective efficacy, hidden profiles, and trust. However, future research is needed in order to verify the results and make them more generalizable to all kinds of groups from different places. 


\section{Suggestions for Future Research}

Given the factors that emerged from the data set, ongoing studies of how these factors specifically lead to groupthink by conducting mixed quantitative and qualitative research are recommended. This research should be complimented with qualitative analysis because, by receiving direct responses from participants about how they felt during their group experience, one might be able to create more in-depth themes, and more or less factors may emerge. Focus groups, personal interviews, and open-ended questionnaires would generate a better understanding of how groups operate, how groupthink can become a very real risk, and how it can best be avoided. According to Schuman and Presser (1979), open-ended questions are useful in discovering spontaneous and original responses, and providing a realistic picture of participants' attitudes, beliefs, and experiences. Additionally, this type of deeper explanation would help expand the practical implications of this research to best represent and address groups from all walks of life.

Next, this study should be replicated with an even larger sample size in both types of participant groups in order to verify the findings and allow for demographic variables to better be accounted for. Participant group sizes should also try to be intentionally increased to allow for a better comparison of face-to-face and virtual or dispersed groups in regard to groupthink. Future research could also conduct studies in different types of communities or regions to create a greater understanding of all kinds of groups. As this line of research continues, it will continue to be important to determine what exactly predicts groupthink and what can be implemented to subdue it. Most people are in some type of group in everyday life, where the risks associated with groupthink are often 
present and very real. It is important to understand what leads to groupthink and how it can be prevented. By realizing how one can improve upon the skills associated with avoiding these variables in a group, one can become more satisfied and productive in their group, and better enjoy their group experience.

Before getting into the final area of future research identified, the problematic nature and catch-22 surrounding groupthink should be addressed and understood in relation to potential measurement problems. As previous literature has shown, what seems to lead to groupthink does not always cause it (e.g., Flippen, 1999; Hirokawa et al., 1988; Kramer \& Dougherty, 2013). Groupthink seems to be somewhat dependent upon random chance or bad luck. Therefore, it is plausible to think that even if research is able to account for the right predictors of the phenomenon, we may never have a completely predictive measure for groupthink that accounts for a large amount of the variance. A high variance in this line of research just may not ever be able to be expected. Additionally, if this research consistently achieves statistical significance and low pvalues, it is possible that due to the low variances likely to arise in this area, there is the potential for false positive results. Again, due to the natural problems with this concept, this risk toward a false positive may be something that researchers in this area will just have to live with. Either way, these results cannot and should not be ignored just because of low variances, since they suggest that something else may be happening, and if that is ignored, then there may be the opposite problem of a false negative.

Due to the above discussion, a final area of future research relates to the low variances accounted for in the two multiple linear regression models. The Groupthink Occurrence model accounted for a statistically significant portion of variance $(6.1 \%)$, 
while the Groupthink Disaster model also accounted for a statistically significant portion of variance (15.3\%). Future research should take a step toward understanding and identifying the final $93.9 \%$ and $84.7 \%$, respectively, of the variance in problematic decision-making within these models. Additionally, this hints at the important difference between "statistical significance," and something simply being "significant." Therefore, future research should also address the limitations of the current study, in an effort to come up with different ways to measure the rest of the variance in groupthink. Possible solutions might be to increase the sample size in each group of participants (students and working adults) in order to achieve a more stable factor structure in the scales and subscales identified through EFA. Finally, future research should analyze the demographic questions asked at the beginning of the present survey instrument in an effort to explore the role of such items on understanding groupthink and its associated predictors.

\section{Conclusion}

The present study tested a new survey instrument for advancing the study of groupthink and its predictors. The results represent one step in the ever-growing process of developing an appropriate and reliable measure concerning groupthink. Additionally, results revealed that the various scales and subscales developed in the study are capable of tapping into the variable of interest, groupthink, with regard to both Groupthink Occurrence and Groupthink Disaster. From here, future studies are needed to explore the variables addressed in this project in greater detail and examine the possibility of other variables that might influence groupthink. Nevertheless, the findings revealed here indicate progress in this line of research and raise other questions which can be addressed 
in the future. At the very least, a new survey instrument for exploring groupthink has withstood the scrutiny of factor analysis procedures and reliability analysis. Furthermore, statistically significant predictors of groupthink, such as collective efficacy, trust, highly cohesive groups, anxiety, and conformity have been identified through the regression models. The Groupthink Occurrence model also identified promotional leadership as a contributing predictor. The current investigation explored the impact of eight predictor variables, highly cohesive groups, promotional leadership, conformity, concurrence seeking anxiety, collective efficacy, hidden profiles, and trust, on groupthink. While further research is needed to confirm the findings, this research suggests that collective efficacy, trust, highly cohesive groups, promotional leadership, anxiety, and conformity can work together towards increasing a group's propensity toward committing groupthink. All group members can work together to address and prevent groupthink. Specifically, all parties involved should understand the role the phenomenon plays in dysfunctional decision-making and poor decision outcomes, and how the predictors identified in this study aid it. Through a greater understanding of what causes groupthink, one can enhance their group experiences, overall satisfaction, and productivity in group work. 


\section{REFERENCES}

Ahlfinger, N. R., \& Esser, J. K. (2001). Testing the groupthink model: Effects of promotional leadership and conformity predisposition. Social Behavior and Personality, 29, 31-42. doi: http://dx.doi.org/10.2224/sbp.2001.29.1.31

Aldag, R., \& Fuller, S. (1993). Beyond fiasco: A reappraisal of the groupthink phenomenon. Psychological Bulletin, 113, 533-552. doi: 10.1037/00332909.113.3.533

Anderson, C. M., \& Martin, M. M. (1999). The relationship of argumentativeness and verbal aggressiveness to cohesion, consensus, and satisfaction in small groups. Communication Reports, 12, 21-31. doi: 10.1080/08934219909367705

Bandura, A. (1977). Social learning theory. Englewood Cliffs, NJ: Prentice Hall.

Bandura, A. (1982). The self and mechanisms of agency. In J. Suls (Ed.), Psychological perspectives on the self. Hillsdale, NJ: Erlbaum.

Bandura, A. (1986). Social foundations of thought and action: A social cognitive view. Englewood Cliffs, NJ: Prentice Hall.

Bandura, A. (1997). Self-efficacy: The exercise of control. New York, NY: Freeman.

Bandura, A., \& Jourden, F. J. (1991). Self-regulatory mechanisms governing the impact of social comparison on complex decision making. Journal of Personality and Social Psychology, 60, 941-951. doi: 10.1037/0022-3514.60.6.941 
Baradell, J. G., \& Klein, K. (1993). Relationship of life stress and body consciousness to hypervigilant decision making. Journal of Personality and Social Psychology, 64, 267-273. doi: 10.1037/0022-3514.64.2.267

Baron, R. S. (2005). So right its wrong: Groupthink and the ubiquitous nature of polarized group decision making. Advances in Experimental Social Psychology, 37, 219-253. doi: 10.1016/S0065-2601(05)37004-3

Bernthal, P. R., \& Insko, C. A. (1993). Cohesiveness without groupthink: The interactive effects of social and task cohesion. Group \& Organizational Management, 18, 6687. doi: 10.1177/1059601193181005

Bonito, J. A., DeCamp, M. H., \& Ruppel, E. K. (2008). The process of information sharing in small groups: Application of a local model. Communication Monographs, 75, 136-157. doi: 10.1080/03637750802082078

Brawley, L. R., Carron, A. V., \& Widmeyer, W. N. (1987). Assessing the cohesion of teams: Validity of the Group Environment Questionnaire. Journal of Sport \& Exercise Psychology, 9(3), 275-294. Retrieved from http://journals.humankinetics.com.

Brawley. L. R., Carron, A. V., \& Widmeyer, W. N. (1988). Exploring the relationship between cohesion and group resistance to disruption. Journal of Sport \& Exercise Psychology, 10(2), 199-213. Retrieved from http://journals.humankinetics.com

Brawley, L. R., Carron, A. V., \& Widmeyer, W. N. (1993). The influence of the group and its cohesiveness on perceptions of group-related variables. Journal of Sport \& Exercise Psychology, 15(3), 245-260. Retrieved from http://journals.humankinetics.com 
Buys, C. L. (1978). Humans would do better without groups. Personality and Social Psychology Bulletin, 4, 123-125. doi: 10.1177/014616727800400126

Callaway, M. R., \& Esser, J. K. (1984). Groupthink: Effects of cohesiveness and problem solving procedures on group decision making. Social Behavior and Personality, 12(2), 157-164. doi: 10.2224/sbp.1984.12.2.157

Callaway, M. R., Marriott, R. G., \& Esser, J. K. (1985). Effects of dominance on group decision making: Toward a stress reduction explanation of groupthink. Journal of Personality and Social Psychology, 49, 949-952. doi:

10.1037/00223514.49.4.949

Carlson, J., \& Hatfield, E. (1992). Psychology of Emotion. Fort Worth, TX: Harcourt Brace Jovanovich.

Chapman, J. (2006). Anxiety and defective decision making: An elaboration of the groupthink model. Management Decision, 44, 1391-1404. doi:

$10.1108 / 00251740610715713$

Cline, R. J. W. (1990). Detecting groupthink: Methods for observing the illusion of unanimity. Communication Quarterly, 38(2), 112-126. doi: $10.1080 / 01463379009369748$

Cohen, J. (1997). Deliberation and democratic legitimacy. In J. F. Bohman \& W. Rehg (Eds.), Deliberative democracy: Essays on reason and politics (pp. 67-91). Cambridge, MA: MIT Press.

Cohen, L. J., \& DeBendedet, A. T. (2012). Penn State cover-up: Groupthink in action. Time.com. Retrieved from http://ideas.time.com/2012/07/17/penn-state-cover-upgroup-think-in-action/ 
Courtright, J. A. (1978). A laboratory investigation of groupthink. Communication Monographs, 45, 229-246. doi: 10.1080/03637757809375968

Cruz, M. G., Boster, F. J., \& Rodriquez, J. I. (1997). The impact of group size and proportion of shared information on the exchange and integration of information in groups. Communication Research, 24, 291-313. doi: $10.1177 / 009365097024003004$

Cruz, M. G., Henningsen, D. D., \& Smith, B. A. (1999). The impact of directive leadership on group information sampling, decisions, and perceptions of the leader. Communication Research, 26, 349-369. doi:

$10.1177 / 009365099026003004$

DeVellis, R. F. (2003). Scale development: Theory and applications ( $2^{\text {nd }}$ ed.): Vol 26. Applied social research methods series. Thousand Oaks, CA: Sage.

de Vaus, D. (2001). Research design in social research. London: Sage.

Earley, P. C. (1993). East meets west meets Mideast: Further explorations of collectivistic and individualistic work groups. Academy of Management Journal, 36, 319-348. doi: 10.2307/256525

Eaton, J. (2001). Management communication: The threat of groupthink. Corporate Communications: An International Journal, 6, 183-192. Retrieved from http://www.emeraldinsight.com/journal/ccij

English, H. \& English, A. (1958). A comprehensive dictionary of psychological and psychoanalytic terms. New York, NY: Longmans.

Erdem, F. (2003). Optimal trust and teamwork: From groupthink to teamthink. Work Study, 52(5), 229-233. doi: 10.1108/00438020310485958 
Esser, J. K. (1998). Alive and well after 25 years: A review of groupthink research. Organizational Behavior and Human Decision Processes, 73(2/3), 116-141. doi: $10.1006 /$ obhd.1998.2758

Esser, J. K., \& Lindoerfer, J. S. (1989) Groupthink and the space shuttle Challenger accident: Toward a quantitative case analysis. Journal of Behavioral Decision Making, 2, 167-177. Retrieved from http://onlinelibrary.wiley.com/journal

Evans, G. W., \& Cohen, S. (1987). Environmental stress. In D. Stokols \& I. Althman (Eds.), Handbook of Environmental Psychology. New York, NY: Wiley.

Finkelstein, S. (2003). Why smart executives fail. New York, NY: Viking Press.

Flippen, A. R. (1999). Understanding groupthink from a self-regulatory perspective. Small Group Research, 30, 139-165. doi: 10.1177/104649649903000201

Flowers, M. L. (1977). A laboratory test of some implications of Janis' groupthink hypothesis. Journal of Personality and Social Psychology, 35, 888-896. doi: $10.1037 / 0022-3514.35 .12 .888$

Fodor, E. M., \& Smith, T. (1982). The power motive as an influence on group decision making. Journal of Personality and Social Psychology, 42, 178-185. doi: $10.1037 / 0022-3514.42 .1 .178$

Frey, L. R., Botan, C. H., \& Kreps, G. L. (2000). Investigating communication: An introduction to research methods ( $2^{\text {nd }}$ ed.). Boston, MA: Allyn \& Bacon.

Fuller, S. R., \& Aldag, R. J. (1998). Organizational tonypandy: Lessons from a quarter century of the groupthink fiasco. Organizational Behavior \& Human Decision Processes, 73(2/3), 163-184. doi: 10.1006/obhd.1998.2760 
Garling, T., Biel, A., \& Gustafsson, M. (1998). Different kinds and roles of environmental uncertainty. Journal of Environmental Psychology, 18, 75-83. doi: 10.1006/jevp.1998.0088

Glaser, R. O. (1993). Groupthink index: Can we manage our agreements?: Facilitator guide. King of Prussia, PA: Organization Design and Development.

Greitmeyer, T., \& Schulz-Hardt, S. (2003). Preference-consistent evaluation of information in the hidden profile paradigm: Beyond group-level explanation for the dominance of shared information in group decisions. Journal of Personality and Social Psychology, 84, 322-339. doi: 10.1037/0022-3514.84.2.322

Gunnarsson, M. (2010). Group decision making. Frederick, MD: Verlag.

Guzzo, R. A., Wagner, D. B., Maguire, E., Herr, B., \& Hawley, C. (1986). Implicit theories and the evaluation of group process and performance. Organizational Behavior \& Human Decision Processes, 37, 279-295. doi: http://dx.doi.org/10.1016/0749-5978(86)900567

Hackman, J. R. (1992). Group influences on individuals in organizations. In M. D. Dunnet \& L. M. Hough (Eds.), Handbook of industrial and organizational psychology (pp. 199-267). Palo Alto, CA: Consulting Psychologists Press.

Henningsen, D. D., \& Henningsen, M. L. M. (2003). Examining social influence in information sharing contexts. Small Group Research, 34, 391-412. doi: $10.1177 / 1046496403251933$

Henningsen, D. D., Henningsen, M. L. M., Eden, J., \& Cruz, M. G. (2006). Examining the symptoms of groupthink and retrospective sensemaking. Small Group Research, 37, 36-64. doi: 10.1177/1046496405281772 
Henningsen, M. L. M. (April 2002). Groupthought: Analysis and reconceptualization of groupthink. Paper presented at the annual meeting of the Central States Communication Association, Milwaukee, WI.

Hensley, T. R., \& Griffin, G. W. (1986). Victims of groupthink: The Kent State University Board of Trustees and the 1977 gymnasium controversy. The Journal of Conflict Resolution, 30, 497-531. doi: 10.1177/0022002786030003006

Hinkle, D. E., Wiersma, W., \& Jurs, S. G. (2003). Applied statistics for the behavioral sciences $\left(5^{\text {th }}\right.$ ed.). Boston, MA: Houghton Mifflin.

Hirokawa, R. Y. Gouran, D. S., \& Martz, A. E. (1988). Understanding the sources of faulty group decision making: A lesson from the Challenger disaster. Small Group Research, 19, 411-433. doi: 10.1177/104649648801900401

Hodges, L., \& Caron, A. V. (1992). Collective Efficacy and group performance. International Journal of Sport \& Exercise Psychology, 23, 48-59. Retrieved from http://journals.humankinetics.com

Hogg, M. A. (1992). The social psychology of group cohesiveness: From attraction to social identity. New York, NY: New York University Press.

Hogg, M. A., \& Hains, S. C. (1998). Friendship and group identification: a new look at the role of cohesiveness in groupthink. European Journal of Social Psychology, 28, 323-341. Retrieved from http://www.easp.eu/publications/journal.htm

Isen, A. M., \& Patrick, R. (1983). The effects of positive feelings on risk taking: when the chips are down. Organizational Behavior and Human Performance, 31(2), 194-202. doi: 10.1016/0030-5073(83)90120-4

Janis, I. L. (1972). Victims of groupthink. Boston, MA: Houghton Mifflin. 
Janis, I. L. (1982). Groupthink: Psychological studies of policy decisions and fiascoes $\left(2^{\text {nd }}\right.$ ed.). Boston, MA: Houghton Mifflin.

Janis, I. L. (1989). Crucial decisions: Leadership in policymaking and crisis management. New York, NY: Free Press.

Janis, I. L., \& Mann, L. (1977). Decision making: A psychological analysis of conflict, choice, and commitment. New York, NY: Free Press.

Johnson, M. A. (1989). Concern for appropriateness scale and behavioral conformity. Journal of Personality Assessment, 53, 567-574. doi:

10.1207/s15327752jpa5303_13

Jones, G. R., \& George, J. M. (1998).The experience and evolution of trust: Implications for cooperation and teamwork. Academy of Management Review, 23, 531-546. Retrieved from http://aom.org/Publications/AMR/Academy-of-ManagementReview.aspx

Koerber, C. P., \& Neck, C. P. (2003). Groupthink and sports: An application of Whyte's model. International Journal of Contemporary Hospitality Management, 15, 2028. doi: $10.1108 / 09596110310458954$

Kozub, S. A. (1993). Exploring the relationship among coaching behavior, team cohesion and player leadership. Unpublished doctoral dissertation. University of Houston, TX.

Kramer, R. (1998). Revisiting the Bay of Pigs and Vietnam decisions after 25 years. Organizational Behavior and Human Decision Processes, 73, 185-209. doi: 10.1006/obhd.1998.2762 
Kramer, M. W., \& Dougherty, D. S. (2013). Groupthink as communication process, not outcome. Communication and Social Change, 1, 44-62. doi: 10.4471/csc.2013.03

Kroon, M. B. R., Hart, P., \& Kreveld, D. V. (1991). Managing group decision making processes: Individual versus collective accountability and groupthink. The International Journal of Conflict Management, 2(2), 91-115. doi: 10.1108/eb022695

Kroon, M. B. R., Kreveld, D. V., \& Rabbie, J. M. (1992). Group versus individual decision making: Effects of accountability and gender on groupthink. Small Group Research, 23, 427-458. doi: 10.1177/1046496492234001

Kuvaas, B., \& Kaufmann, G. (2004). Impact of mood, framing, and need for cognition and decision makers' recall and confidence. Journal of Behavioral Decision Making, 17, 59-74. doi: 10.1002/bdm.461

Larson, J. R., Jr., Foster-Fishman, P. G., \& Franz, T. M. (1998). Leadership style and the discussion of shared and unshared information in decision-making groups. Personality and Social Psychology Bulletin, 24, 482-495. doi:

$10.1177 / 0146167298245004$

Leana, C. R. (1985). A partial test of Janis' groupthink model: Effects of group cohesiveness and leader behavior on defective decision making. Journal of Management, 11, 5-17. doi: 10.1177/014920638501100102

Leighter, J. L., \& Black, L. (2010). "I'm just raising the question”: Terms for talk and practical metadiscursive argument in public meetings. Western Journal of Communication, 74, 547-569. doi: 10.1080/10570314.2010.512281 
Lennox, R. D., \& Wolfe, R. N. (1984). Revision of the self-monitoring scale. Journal of Personality and Social Psychology, 46, 1349-1364. doi:

$10.1037 / 00223514.46 .6 .1349$

Leon, M. R., \& Revelle, W. (1985). Effects of anxiety on analogical reasoning: A test of three theoretical models. Journal of Personality and Social Psychology, 49, 13021315. doi: $10.1037 / 0022-3514.49 .5 .1302$

Lindsley, D. H., Brass, D. J., \& Thomas, J. B. (1995). Efficacy-performance spirals: A multi-level perspective. Academy of Management Review, 20, 645-678. doi: 10.5465/AMR.1995.9508080333

Longley, J., \& Pruitt, D. G. (1980). Groupthink: A critique of Janis' theory. In L. Wheeler (Eds.), Review of Personality and Social Psychology. Beverly Hills, CA: Sage.

Louis, M. R. (1990). Acculturation in the workplace: Newcomers as lay ethnographers. In B. Schneider (Eds.), Organizational climate and culture (pp. 85-129). San Francisco, CA: Jossey-Bass.

Mano, H. (1992). Judgment under distress: Assessing the role of unpleasantness and arousal in judgment formation. Organizational Behavior and Human Decision Processes, 52, 216-245. doi: 10.1016/0749-5978(92)90036-7

Mano, H. (1994). Risk-taking, framing effects, and affect. Organizational Behavior and Human Decision Processes, 57, 38-58. doi: 10.1006/obhd.1994.1003

Manz, C. C., \& Neck, C. P. (1995). Teamthink: Beyond the groupthink syndrome in selfmanaging work teams. Journal of Managerial Psychology, 10, 7-15. doi: $10.1108 / 02683949510075155$ 
McCauley, C. (1989). The nature of social influence in groupthink: Compliance and internalization. Journal of Personality and Social Psychology, 57, 250-260. doi: $10.1037 / 0022-3514.57 .2 .250$

McCauley, C. (1998). Group dynamics in Janis' theory of groupthink. Organization Behavior and Human Decision Processes, 73, 142-162. doi: 10.1006/obhd.1998.2759

Mertler, C. A., \& Vannatta, R. A. (2005). Advanced and multivariate statistical methods: Practical application and interpretation ( $3^{\text {rd }}$ ed.). Glendale, CA: Pyrczak.

Meyers, L. S., Gamst, G., \& Guarino, A. J. (2006). Applied multivariate research: Design and interpretation. Thousand Oaks, CA: Sage.

Miles, J., \& Shevlin, M. (2001). Applying regression and correlation: A guide for students and researchers. London, UK: Sage.

Miller, D. (1990). The Icarus paradox: How exceptional companies bring about their own downfall. New York, NY: Harper Business.

Mittal, V., \& Ross, W. T. (1998). The impact of positive and negative affect and issue framing on issue interpretation and risk taking. Organizational Behavior and Human Decision Processes, 76, 298-324. doi: 0.1006/obhd.1998.2808

Moorhead, G., \& Montanari, J. R. (1986). An empirical investigation of the groupthink phenomenon. Human Relations, 39, 399-410. doi: 10.1177/001872678603900502

Moorhead, G., Ference, R., \& Neck, C. P. (1991). Group decision fiascoes continue: Space shuttle Challenger and a revised framework. Human Relations, 44, 539550. doi: 10.1177/001872679104400601 
Moreland, R. L. (2010). Are dyads really groups? Small Group Research, 41, 251-267. doi: $10.1177 / 1046496409358618$

Mullen, B., \& Copper, C. (1994). The relationship between group cohesiveness and performance: An integration. Psychological Bulletin, 115(2), 210-227. doi: 10.1037/0033-2909.115.2.210

Neck, C. P. (1996). Letterman or Leno: A groupthink analysis of successive decisions made by the National Broadcasting Company. Journal of Managerial Psychology, 11(8), 3-17. doi: 10.1108/02683949610150024

Neck, C. P., Godwin, J. L., \& Spencer, E. S. (1996). Understand research “projection” in interpreting case study data: The South Canyon fire tragedy. Journal of Applied Behavioral Science, 32, 48-61. doi: 10.1177/0021886396321003

Neck, C. P., \& Moorhead, G. (1992). Jury deliberations in the trial of US v. John DeLorean: A case study analysis of groupthink avoidance and an enhanced framework. Human Relations, 45, 1077-1091. doi: 10.1177/001872679204501004

Neck, C. P., \& Moorhead, G. (1995). Groupthink remodeled: The importance of leadership, time pressure, and methodical decision-making procedures. Human Relations, 48, 537-557. doi: 10.1177/001872679504800505

Park, W. (2000). A comprehensive empirical investigation of the relationship among variables in the groupthink model. Organizational Behavior \& Human Decision Processes, 21, 873-887. Retrieved from http://www.journals.elsevier.com/organizational-behavior-and-human-decisionprocesses/ 
Paskevich, D. M., Brawley, L. R., Dorsch, K. D., \& Widmeyer, W. N. (1999).

Relationship between collective efficacy and team cohesion: Conceptual and measurement issues. Group Dynamics: Theory, Research, and Practice, 3, 210222. doi: 10.1037/1089-2699.3.3.210

Paskevich, D. M., Estabrooks, P., Brawley, L. R., \& Carron, A. V. (2001). Group cohesion in sport and exercise. In R. Singer, H. Hausenblas, \& C. Janelle (Eds.), Handbook of sport psychology ( $2^{\text {nd }}$ ed., pp. 472-494). New York, NY: John Wiley.

Paulus, P. B. (1998). Developing consensus about groupthink after all these years. Organizational Behavior and Human Decision Processes, 73, 362-374. doi: http://dx .doi.org/10.1006/obhd.1998.2767

Peterson, R. S., Owens, P. D., Tetlock, P. E., Fan, E. T., \& Martorana, P. (1998). Group dynamics in top management teams: Groupthink, vigilance, and alternative models of organizational failure and success. Organizational Behavior and Human Decision Processes, 73, 272-305. doi: 10.1006/obhd.1998.2763

Prapavessis, H., \& Carron, A. V. (1997). Cohesion and work output. Small Group Research, 28, 294-301. doi: 10.1177/1046496497282006

Prussia, G. E., \& Kinicki, A. J. (1996). A motivational investigation of group effectiveness using social-cognitive theory. Journal of Applied Psychology, 81(2), 187-198. doi: 10.1037/0021-9010.81.2.187

Raven, B. H. (1998). Groupthink, Bay of Pigs, and Watergate reconsidered. Organizational Behavior and Human Decision Processes, 73, 352-361. doi: http://dx.doi.org/10.1006/obhd.1998.2766 
Riggs, M. L., Warka, J., Babasa, B., Betancourt, R., \& Hooker, S. (1994). Development and validation of self-efficacy and outcome expectancy scales for job related applications. Educational and Psychological Measurement, 54, 793-802. doi:

$10.1177 / 0013164494054003026$

Robbins, S. P., \& Judge, T. A. (2011). Organizational behavior. Upper Saddle River, NJ: Prentice Hall.

Rose, J. D. (2011). Diverse perspectives on the groupthink theory - A literary review. Emerging Leadership Journeys, 4, 37-57. Retrieved from http://www.regent.edu/acad/global/publications/

Rycroft, C. (1968), Anxiety and Neurosis. Harmondsworth, UK: Basic Books.

Ryfe, D. M. (2005). Does deliberative democracy work? The Annual Review of Political Science, 8, 49-71. doi: 10.1146/annurev.polisci.8.032904.154633

Schuman, H., \& Presser, S. (1979). The open and closed question. American Sociological Review, 44, 692-712. Retrieved from http://www.jstor.org/stable/2094521

Shields, D. L. L., Bredemeier, B. J. L., Gardner, D. E., \& Boston, A. (1995). Leadership, cohesion, and team norms regarding cheating and aggression. Sociology of Sport Journal, 12, 324-336. Retrieved from http://www.nasss.org/journal/

Sitkin, S. (1992). Learning from failure: The strategy of small losses. In B. M. Staw \& L. L. Cummings (Eds.), Research in organizational behavior. Greenwich, CT: JAI Press.

Stasser, G., \& Birchmeier, Z. (2003). Group creativity and collective choice. In P. B. Paulus \& B. A. Nijstad (Eds.), Group creativity: Innovation through collaboration (pp. 85-109). Oxford, UK: Oxford University Press. 
Stasser, G., \& Titus, W. (1985). Pooling of unshared information in group decision making: Biased information sampling during discussion. Journal of Personality and Social Psychology, 48, 1467-1478. doi: 10.1037/0022-3514.48.6.1467

Stasser, G., \& Titus, W. (2003). Hidden profiles: A brief history. Psychology Inquiry, 14, 304-313. doi: 10.1080/1047840X.2003.9682897

Staw, B. M., \& Ross, J. (1987). Behavior in escalation situations: Antecedents, prototypes, and solutions. In L. L. Cummings \& B. M. Staw (Eds.), Research in organizational behavior. Greenwich, CT: JAI Press.

Tasa, K., \& Whyte, G. (2005). Collective efficacy and vigilant problem solving in group decision making: A non-linear model. Organizational Behavior and Human Decision Processes, 96, 119-129. doi: 10.1016/j.obhdp.2005.01.002

Tetlock, P.E., Peterson, R. S., McGuire, C., Chang, S., \& Field, P. (1992). Assessing political group dynamics: A test of the groupthink model. Journal of Personality and Social Psychology, 63, 403-425. doi: http://dx.doi.org/10.1037/00223514.63.3.403

Turner, M. E., \& Pratkanis, A. R. (1998). Twenty-five years of groupthink theory and research. Organizational Behavior and Human Decision Processes, 73, 105-115. doi: 10.1006/obhd.1998.2756

Turner, M. E., Pratkanis, A. R., Probasco, P., \& Leve, C. (1992). Threat, cohesion, and group effectiveness: Testing a social identity maintenance perspective on groupthink. Journal of Personality and Social Psychology, 63, 781-796. doi: $10.1037 / 0022-3514.63 .5 .781$ 
Westre, K. R., \& Weiss, M. R. (1991). The relationship between perceived coaching and group cohesion in high school football teams. The Social Psychologist, 5, 41-54. Retrieved from http://journals.humankinetics.com/

Whyte, G. (1998). Recasting Janis' groupthink model: The key role of collective efficacy in decision fiascos. Organizational Behavior and Human Decision Processes, 73, 185-209. doi: 10.1006/obhd.1998.2761

Whyte, G., Saks, A., \& Hook, S. (1997). When success breeds failure: The role of selfefficacy in escalating commitment to a losing course of action. Journal of Organizational Behavior and Human Decision Processes, 18, 415-432. Retrieved from http://www.journals.elsevier.com/organizational-behavior-and-humandecision-processes

Widmeyer, W. N., Brawley, L. R., \& Carron, A. V. (1990). The effects of group size in sport. Journal of Sport \& Exercise Psychology, 12(2), 177-190. Retrieved from http://journals.humankinetics.com

Williams, J. M., \& Hacker, C. M. (1982). Causal relationship among cohesion, satisfaction, and performance in women's intercollegiate field hockey teams. Journal of Sport \& Exercise Psychology, 4, 324-337. Retrieved from http://journals.humankinetics.com/

Wolfe, R. N., Lennox, R. D., \& Cutler, B. L. (1986). Getting along and getting ahead: Empirical support for a theory of protective and acquisitive self-presentation. Journal of Personality and Social Psychology, 50, 356-361. doi: 10.1037/00223514.50.2.356 
Wolfe, R. N., Welch, L. K., Lennox, R. D., \& Cutler, B. L. (1985). Concern for appropriateness as a moderator variable in the statistical explanation of the self reported use of alcohol and marijuana. Journal of Personality, 53, 1-16. doi: 10.1111/j.14676494.1985.tb00884.x 


\section{APPENDIX}

\section{SURVEY QUESTIONS}

Directions: Please think of past group or team experiences you have had where your group made a bad decision. Of those experiences, please focus on the worst decision a group or team you have been a member of has made. Then, answer the following questions with that specific group or team experience in mind (the group or team that made the worst decision). Please continue to keep this particular group or team experience in mind as you fill out the rest of this survey.

1. What was the approximate size of this group or team? (number slider?)

2. How long had the group or team worked together before this bad decision was made? (text box)

3. What type of group or team was this? (multiple response checkboxes; check all that apply) Business related in Bloomington-Normal, Class Work Group, Registered Student Organization, Academic/Honorary group, Greek Life, Search Committee, Panel, Thesis Committee, Scholarship Committee, Sports Team, other. (If other, please explain)

4. Was this group or team a decision-making group?

5. Did this group or team meet mostly face-to-face or virtually (e.g., skype)?

Directions: Keeping this group or team experience in mind, please indicate how much you agree with the following statements from 1 (strongly disagree) to 5 (strongly agree).

\section{Highly Cohesive}

6. Our group communicated a high degree of shared interest.

7. I would consider our group to be highly cohesive.

8. Our group had a lack of diversity in member's abilities and talents.

9. Members of our group had worked together before.

10. Our group respected other's viewpoints.

11. Our group ignored opposing viewpoints. [Recoded]

12. Our group focused more on staying together than on making the best decision.

13. Our group focused less on harmony than on making the right decision. [Recoded]

14. Members of the group indicated they shared many of the same values.

\section{Promotional Leadership}

15. Our group leader was impartial. [Recoded]

16. Our group leader expressed her/his opinion often.

17. Our group leader encouraged others to express their own ideas. [Recoded] 
18. Our leader stated her/his preference up front.

19. Our leader made sure her/his opinion did not hold more weight than the group's opinion as a whole. [Recoded]

20. Our group leader pushed her/his decision over others.

21 . The leader strongly influenced the final group decision.

22. The group often deferred to the opinions of the leader.

23. Our group discussed fewer facts because of our leader had already made her/his position clear.

24. Because of our leader's comments, our group reached a decision too quickly.

25. Our leader was approachable. [Recoded]

\section{Conformity}

26. I often agreed openly with the group's decision, even if I disagreed privately.

27. I felt a pressure to agree with the group's opinions.

28. I often kept my opinions to myself.

29. I felt free to express any concerns I had with the ideas that were proposed. [Recoded]

30. I felt comfortable asking questions about a solution. [Recoded]

31. I often failed to express disagreement with what someone else said.

32. I had doubts about the group's decision, but did not say anything.

33. I voiced doubts about the group's decision. [Recoded]

34. Our group had a culture of withholding our own opinions.

35. Members of the group often asked questions to present other points of view or play the role of the devil's advocate (which is someone who questions ideas to make sure it is the right choice). [Recoded]

36. There were many disagreements within the group. [Recoded]

37. Everyone in the group had a voice. [Recoded]

\section{Concurrence Seeking}

38. I felt pressure from the group to not "rock the boat."

39. I felt pressure to just go along with the group's preferred decision.

40. Members of the group acted as mindguards, protecting the group leader or the preferred group decision from others.

41. Group members began looking for a consensus before a proposed solution was fully analyzed.

42. The group pressured members to agree with each other.

43. As a group, we failed to fully acknowledge the opinions of those with a particular expertise in a given area.

44. At least one person at each meeting played the role of the devil's advocate. [Recoded]

45. There was a lot of pressure from the group to make decisions quickly.

46. The group encouraged members to express any reservations they had about the group decision. [Recoded]

47. Some group members prevented others from expressing opposing points of view.

48. Our group promoted the importance of reaching a consensus. 
49. When I spoke up about any doubts I had, my fellow group members seriously listened to me. [Recoded]

50. We often felt our group decisions were unanimous.

\section{Anxiety}

51. Our group dealt with a lot of expressed stress and anxiety.

52. Our group's decision involved risk.

53. Our group's decision involved a moral dilemma.

54. Our group had failed previously, which added to our expressed stress.

55. Our group provided support to help members cope with expressed stress. [Recoded]

56. Our group's expressed stress was intensified because of how close we were with each other.

57. Our group took more risks because of the stress we felt.

58. Because of our anxiety, our group was frantic in trying to make a decision.

59. Our group failed to consider all possible alternatives to our decision due to the pressures of expressed stress and anxiety.

60. Our group tried to escape from the stressful situation as quickly as we could.

61. Members of the group became defensive due to expressed stress.

62. I felt fear or anxiety over our group's task.

\section{Collective Efficacy}

63. Our group expressed confidence with our decision.

64. Our group was overly confident with our decision.

65. Our group became complacent with our decision-making process.

66. Our group took risks in making our decision.

67. Our group communicated a "can do" attitude.

68. Our group believed in its ability to execute a plan to reach our goals.

69. Our group strongly communicated an ability to complete the task at hand.

70. Our group was not easily discouraged.

71. Our group "stayed the course," even when things looked bad.

72. Our group tended to increase our commitment to losing courses of action, almost being "thick headed."

73. Our group believed we could solve our own problems if we worked together.

74. Our group talked about our prior successes as evidence of our ability to complete the current task.

\section{Hidden Profiles}

75. Everyone in the group shared all of the information they had about a particular problem or task. [Recoded]

76. Our group really only discussed information that was common to everyone.

77. Our group often discussed unique information that not everyone began the discussion with knowledge of. [Recoded]

78. When unique information was contributed, it was recognized and treated as important. [Recoded] 
79. Our group simply chose the option that was initially favored by the group's majority.

80. When information that was inconsistent with the majority opinion was brought up, it was viewed as less important than information consistent with the majority opinion.

81. Our group communicated confidence in our decision because we thought we had all of the information available.

82. Our group was not overly confident because we knew we may be lacking some information. [Recoded]

83. I stopped providing helpful information because I felt I was being ignored.

\section{Trust}

84. There was a mutual sense of trust within the group.

85 . There was too much trust within the group.

86. No one in the group wanted to break the feeling of trust by bringing up opposing ideas.

87. Some group members displayed signs of distrust. [Recoded]

88. Group members expressed their views freely.

89. Our group's environment was supportive.

90. I had confidence in our group members to make the right decision.

91. I often looked to my fellow group members for help.

92. I felt free to exchange information about myself with our group.

93. I shared my resources with group members.

Directions: Keeping the same group or team experience in mind, please answer the following questions about "groupthink." Groupthink is the term used to describe how certain conditions can lead a group to be highly satisfied with what turns out to be an ineffective decision. It is a mode of thinking in which members of a highly cohesive group strive for unanimity and consensus, which overrides their motivation to realistically appraise alternative courses of action. The more cohesiveness a group has, the more pressure it puts onto members of that group to maintain the cohesiveness. In turn, the group invests more of its energy in keeping this cohesiveness intact than it does in making the right decision.

94. Do you believe that your decision-making group or team committed groupthink? (yes, no, maybe) Please explain. (text box)

95. How many times do you believe your group or team committed groupthink? (number slider)

96. How disastrous was the result of your group's or team's decision? (scale from 19)

97. How recently did your group's or team's last instance of groupthink occur? (text box) 


\section{Individual Demographic Information}

98. What is your biological sex?

Male

Female

Other

99. What is your age? (number slider)

100. What is your race/ethnicity?

African American

Native American

Caucasian

Hispanic

Bi-racial/Mixed

Asian/Pacific Islander

Other 